\title{
SUBCRITICAL CALIFORNIUM SOURCE-DRIVEN NOISE ANALYSIS MEASUREMENTS WITH UNREFLECTED URANIUM (93.15) HYDRIDE
}

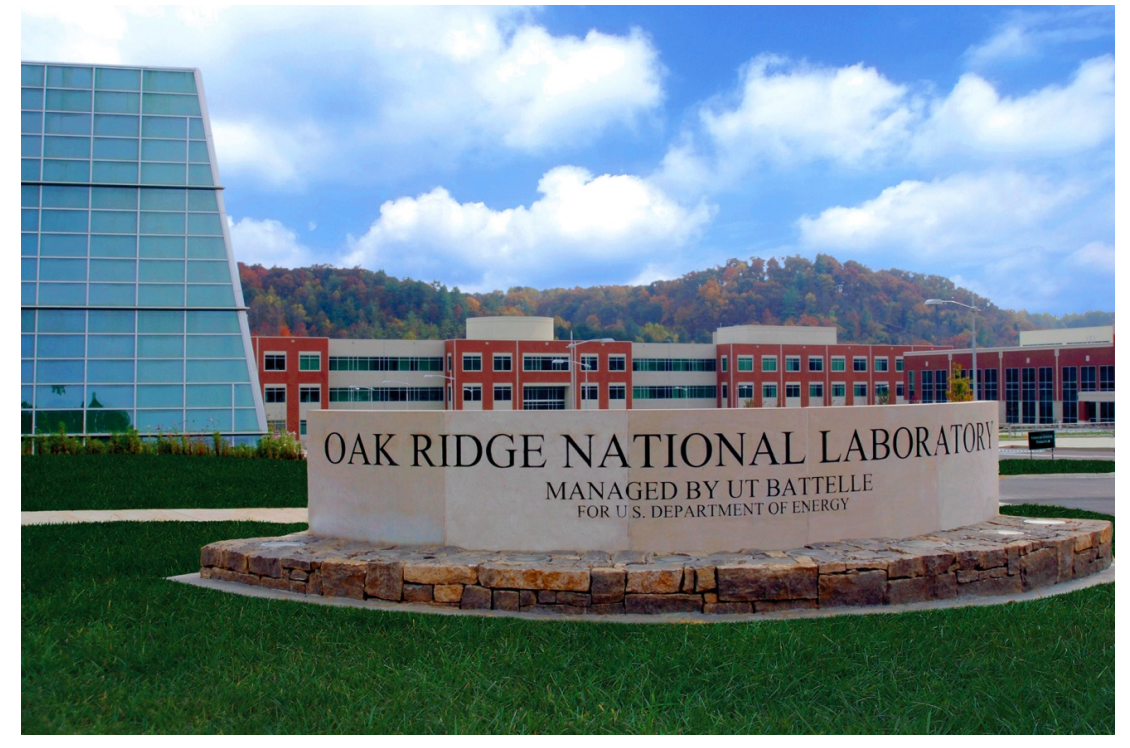

John T. Mihalczo

Approved for public release. Distribution is unlimited.

June 2021 


\section{DOCUMENT AVAILABILITY}

Reports produced after January 1, 1996, are generally available free via US Department of Energy (DOE) SciTech Connect.

Website www.osti.gov

Reports produced before January 1, 1996, may be purchased by members of the public from the following source:

National Technical Information Service

5285 Port Royal Road

Springfield, VA 22161

Telephone 703-605-6000 (1-800-553-6847)

TDD 703-487-4639

Fax 703-605-6900

E-mail info@ntis.gov

Website http://classic.ntis.gov/

Reports are available to DOE employees, DOE contractors, Energy Technology Data Exchange representatives, and International Nuclear Information System representatives from the following source:

Office of Scientific and Technical Information

PO Box 62

Oak Ridge, TN 37831

Telephone 865-576-8401

Fax 865-576-5728

E-mail reports@osti.gov

Website https://www.osti.gov/

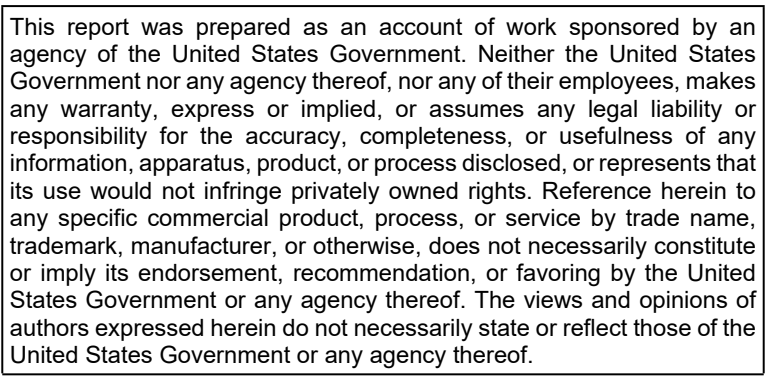


ORNL/TM-2021/1963

Physics Division

SUBCRITICAL CALIFORNIUM SOURCE-DRIVEN NOISE ANALYSIS MEASUREMENTS WITH UNREFLECTED URANIUM (93.15) HYDRIDE

John T. Mihalczo

Aug 2021

OAK RIDGE NATIONAL LABORATORY

Oak Ridge, TN 37831-6283

managed by

UT-BATTELLE LLC

for the

US DEPARTMENT OF ENERGY

under contract DE-AC05-00OR22725 



\section{CONTENTS}

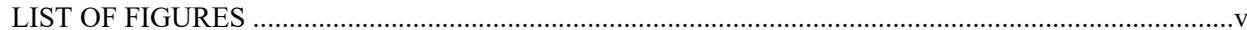

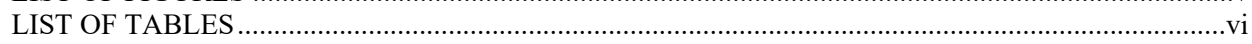

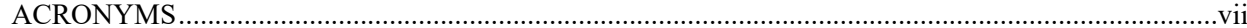

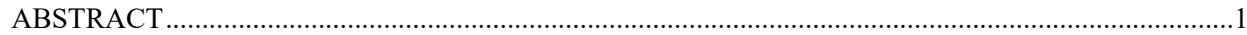

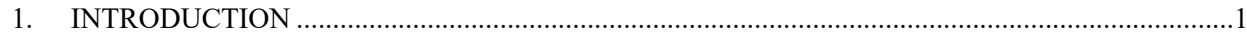

2. DETAILED DESCRIPTION

2.1 OVERVIEW OF EXPERIMENT ..............................................................................2

2.2 SUBCRITICAL BENCHMARKING FOR SUBCRITICAL HYDRIDE CYLINDERS ............2

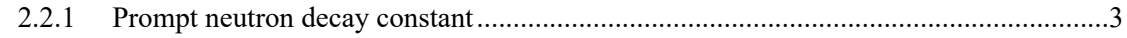

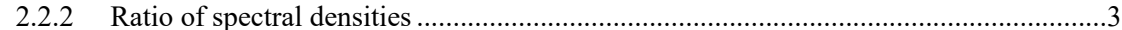

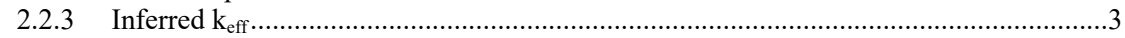

2.3 DESCRIPTION OF EXPERIMENTAL MATERIALS AND CONFIGURATIONS ..............4

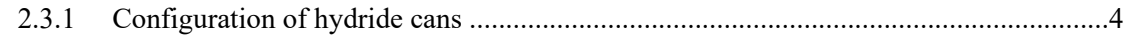

2.3.2 Description of the californium ionization chamber ....................................................

2.3.3 Description of the detectors (mostly from SUB-HEU-SOL-THERM-002) .....................

2.4 DESCRIPTION OF THE MATERIAL (FROM HEU-COMP-INTER-003) ..........................11

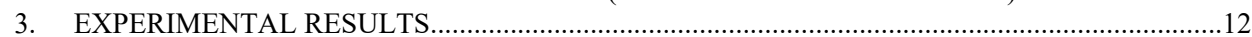

3.1 EXPERIMENTAL CONFIGURATIONS ...................................................................... 12

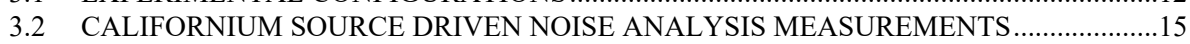

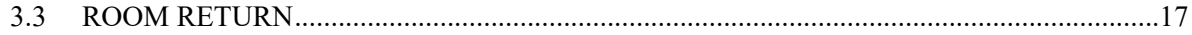

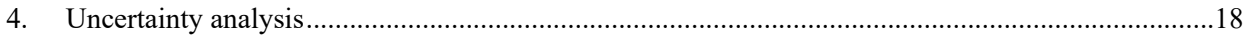

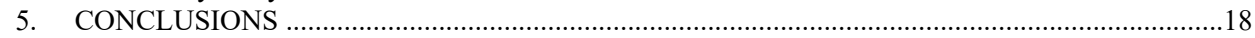

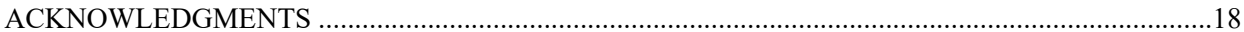

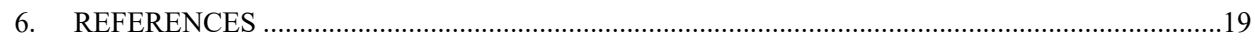

APPENDIX A. FREQUENCY ANALYSIS DATA FOR THE 16 CM HIGH CONFIGURATION

OF URANIUM HYDRIDE CYLINDERS .........................................................................

APPENDIX B. DETAILED SKETCH OF THE CALIFORNIUM IONIZATION CHAMBER .............B-1

APPENDIX C. CALIFORNIUM SOURCE-DRIVEN-NOISE ANALYSIS ..............................................

APPENDIX D. COMPOSITION OF THE CONCRETE ............................................................... 


\section{LIST OF FIGURES}

Figure 1. Description of the uranium hydride cans from HEU-COMP-INTER-003..................................5

Figure 2. Description of the aluminum spacer and steel filler to aid in stacking the cans from HEU-COMP-INTER-003

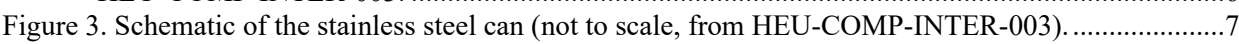

Figure 4. Sketch of the californium ionization chamber (californium deposit not to scale)........................8

Figure 5. Detailed model of the detectors (from SUB-HEU-SOL-THERM-002).......................................9

Figure 6. Composite scintillator configuration (from SUB-HEU-SOL-THERM-002) ..............................10

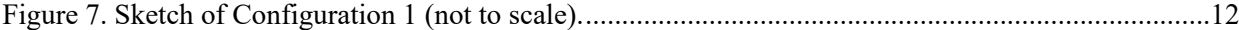

Figure 8. Sketch of Configuration 2 (not to scale).................................................................................13

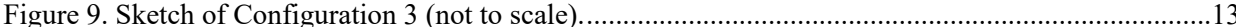

Figure 10. Sketch of Configuration 4 (not to scale)............................................................................

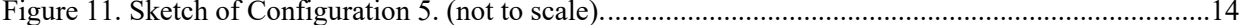

Figure 12. Sketch of Configuration 6 (not to scale)............................................................................15

Figure A.1. Auto power spectral densities for the californium source detection channel (left) and the first detector (right)

Figure A.2. Auto power spectral density for the second detector (left) and the real part of the cross-power spectral density between the first detector and the californium source (right). ........A-2

Figure A.3. Real part of the cross-power spectral density between the second detector and the californium source (left) and the real part of the cross-power spectral densities between the two detectors (right)

Figure A.4. Imaginary part of the cross-power spectral density between the first detector and the californium source (left)and between the second detector and the californium source (right).

Figure A.5. Imaginary part of the cross-power spectral density between the two detectors (left) and the coherence between the first detector and the californium source (right)

Figure A.6. Coherence between the second detector and the californium source (left) and between the two detector (right)

Figure C.1. Highly enriched uranyl nitrate solution tank without external detectors and the californium source at the top of the solution (solution color distorted from actual yellow by red tape on the table behind the tank).

Figure C.2. Comparison of neutron multiplication factors obtained for the Pare/Mihalczo formulation of detection effects from static measurement with two ${ }^{3} \mathrm{He}$ proportional counters adjacent to the tank detecting leakage neutrons and with the source at the bottom of the tank.

Figure C.3. Comparison of neutron multiplication factors obtained for the Pare/Mihalczo formulation of detection effects from dynamic measurement with two fast plastic scintillators adjacent to the tank detecting and gamma rays and the californium source at the bottom of the tank with calculations.

Figure C.4. Comparison of neutron multiplication factors from RACER Monte Carlo calculations with the two formulations.

Figure C 5. Neutron multiplication factors from ratios of spectral densities with both formulations compared with calculations. 


\section{LIST OF TABLES}

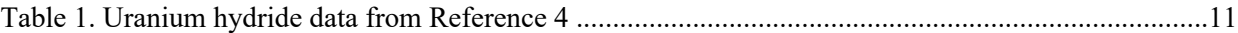

Table 1.a. Specifications for uranium hydride disks from Reference 4 ..................................................11

Table 2. Measured online ratios of spectral densities for cylindrical hydride cans of various

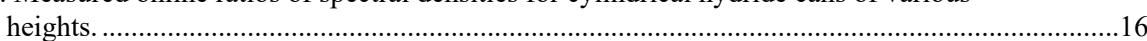

Table 3. Inferred neutron multiplication measurements from the CSDNA measurements .......................17

Table C.1. Measured ratios of spectral densities at low frequencies and neutron multiplication

factors from static measurement with the source at the bottom of the solution. 


\section{ACRONYMS}

$\begin{array}{ll}\text { APSD } & \text { auto power spectral densities } \\ \text { CPSD } & \text { cross-power spectral densities } \\ \text { CSDNA } & \text { californium source-driven noise analysis } \\ \text { ICSBEP } & \text { International Criticality Safety Benchmark Program } \\ \text { LANL } & \text { Los Alamos National Laboratory } \\ \text { NEA } & \text { Nuclear Energy Agency } \\ \text { ORNL } & \text { Oak Ridge National Laboratory } \\ \text { PMT } & \text { photomultiplier tube }\end{array}$




\begin{abstract}
On July 6, 1989, subcritical californium source-driven noise analysis (CSDNA) measurements were performed with bare uranium hydride cylindrical assemblies at the Los Alamos National Laboratory Critical Experiments Facility in KIVA 1. Three configurations of $\sim 7.5 \mathrm{~cm}$ radius-enriched $(93.15$ wt. \% ${ }^{235} \mathrm{U}$ ) uranium hydride with a density of $\sim 10 \mathrm{~g} / \mathrm{cm}^{3}$ cylinders were assembled with uranium hydride heights of $\sim 11, \sim 14$, and $\sim 16 \mathrm{~cm}$. The uranium hydride ( 2 and $\sim 3 \mathrm{~cm}$ high) was in thin-welded stainless steel cans. The neutron multiplication factors obtained on-line from the measured ratios of spectral densities were $0.942 \pm 0.002,0.917 \pm 0.003$, and $0.867 \pm 0.004$ for uranium hydride heights of $\sim 16, \sim 14$, and $\sim 11 \mathrm{~cm}$., respectively. Neutron multiplication factors for these three configurations calculated by Los Alamos National Laboratory Monte Carlo methods were $0.952 \pm 0.005,0.922 \pm 0.005$, and $0.860 \pm 0.005$, all of which are in good agreement with the measurements. The break frequency noise analysis data could be fitted to obtain the prompt neutron decay constant at all subcritical states. Some data presented in this report are from notes that are not in the logbooks. A discussion of the two different point kinetics theories of the measurements that illustrated the deficiencies of the rigorous theory at low neutron multiplication factors $\left(\mathrm{k}_{\mathrm{eff}}<0.80\right)$ is given in an Appendix. These measurements may be the only configuration of unreflected, highly enriched uranium hydride configuration assembled. The presence of hydrogen diluted the uranium density, decreasing the reactivity, but this is offset by slowing down the neutron energy to the energy ranges of higher-fission cross sections. Extrapolations to delayed critical indicate that adding one more $3 \mathrm{~cm}$ can and one more $2 \mathrm{~cm}$ can would result in the unreflected cylindrical system being slightly above critical with a critical mass of $\sim 37 \mathrm{~kg}$, which is considerably less than the critical mass of an unreflected and unmoderated highly enriched uranium metal sphere. An unreflected, highly enriched uranium hydride sphere would have a critical mass less than $37 \mathrm{~kg}$.
\end{abstract}

The purpose of this report is to document the experimental information for the measurements performed so that at a later date researchers could perform the required uncertainty and calculational analyses and documentation to use these data for an International Criticality Safety Benchmark Program (ICSBEP) or Nuclear Energy Agency (NEA) benchmark. The data from these measurements are available from the Records Management Services Department of Oak Ridge National Laboratory (ORNL), and the logbook is available from John Bess at the ICSBEP at Idaho National Laboratory. Previous reflected uranium hydride critical experiments are benchmarked in HEU-COMP-INTER-003 and some of the data presented in that benchmark (particularly the description of the uranium hydride) are relevant and are included here.

\title{
1. INTRODUCTION
}

On July 6, 1989, subcritical Californium source-driven noise analysis (CSDNA) measurements [1] were performed with unreflected uranium hydride cylindrical assemblies at the Los Alamos National Laboratory (LANL) Critical Experiments Facility in KIVA 1. KIVA 1's dimensions are $30 \times 48 \mathrm{ft}$., with a ceiling height of $30 \mathrm{ft}$. Three configurations of $\sim 7.5 \mathrm{~cm}$ radius enriched $\left(93.15 \mathrm{wt} . \%{ }^{235} \mathrm{U}\right)$ uranium hydride with a density of $\sim 10 \mathrm{~g} / \mathrm{cm}^{3}$ cylinders were assembled with uranium hydride heights of $\sim 11, \sim 14$, and $\sim 16 \mathrm{~cm}$. The uranium hydride was in thin-welded stainless steel cans [2]. The californium source was centered adjacent to the top cylindrical can of each configuration, and the detectors were located 180 degrees apart and $6.35 \mathrm{~cm}$ from the radial surface of the cylindrical hydride can assembly. The CSDNA data were interpreted online to obtain the neutron multiplication factor. The measured CSDNA data can be directly calculated for benchmarking [3] or the interpretation to obtain the neutron multiplication factor from the CSDNA data [1]. The direct calculation of the CSDNA data involves less uncertainty because the interpretation to obtain the neutron multiplication factor involves many parameters with their uncertainties. 
The purpose of this report is to document the experimental information for the measurements performed so that at a later date researchers could perform the required uncertainty and calculational analyses and documentation to use these data for an International Criticality Safety Benchmark Program (ICSBEP) or a European Atomic Energy Community (EURATOM) Nuclear Energy Agency (NEA) benchmark. The data from these measurements are available from the Records Management Services Department of Oak Ridge National Laboratory (ORNL), and the logbook is available from the ICSBEP at Idaho National Laboratory.

\section{DETAILED DESCRIPTION}

\subsection{OVERVIEW OF EXPERIMENT}

CSDNA subcritical measurements were performed on July 6, 1989 by ORNL in KIVA 1 at the LANL Critical Experiments Facility for unreflected $\sim 15.0 \mathrm{~cm}$ diameter cylinders of various heights. The ${ }^{235} \mathrm{U}$ enrichment was $92.15 \mathrm{wt} . \%{ }^{235} \mathrm{U}$, and the $\mathrm{H} / \mathrm{U}$ ratio was $\sim 3$. The pressed uranium hydride powder was in thin (0.010-in.-thick) stainless steel cans with a density of the hydride of $\sim 10 \mathrm{~g} / \mathrm{cm}^{3}$. Four $\sim 3.00 \mathrm{~cm}$ high (identified as I, II, III, and IV) and two $\sim 2.0 \mathrm{~cm}$ high (identified as A and B) uranium hydride canned cylinders were available. The center of the $0.5 \mathrm{~cm}$ thick carbon steel table $(18 \times 36 \mathrm{in}$. surface $)$ on which the configurations were assembled was located $3 \mathrm{~m}$ from the nearest two walls which were of concrete block construction with an equivalent concrete thickness of $4.35 \mathrm{in}$. and to the right of the personnel entrance. The hydride cylinder assemblies were hand stacked on $5 \mathrm{~cm}$ high aluminum spacer on a $0.5-\mathrm{cm}$. - thick table whose top was $86 \mathrm{~cm}$ above the concrete floor. Configurations of $\sim 11, \sim 14$, and $\sim 16 \mathrm{~cm}$ height cylinders were assembled with masses of 19,795, 25,264, and 28,858 $\mathrm{g}$ (including the steel cans), respectively [4]. The cans were stacked vertically and there were two variants of the stacking for each nominal height. From the bottom up, the stacking orders for the nominal $\sim 11-\mathrm{cm}$.-high assembly were A, IV, II, and I and B, IV, II, and I. For the $\sim 14-\mathrm{cm}$.-high assembly, the stacking orders were A, III, IV, II, and I and B, III, IV, II, and I. For the $\sim 16-\mathrm{cm}$.-high assembly, the stacking orders were A, B, III, IV, II, and I and B, A, III, IV, II, and I. These variants check reproducibility because the assembly had to be restacked completely for each one. Critical experiments with this uranium hydride material with thin depleted uranium metal, beryllium metal, and iron reflectors on the Comet assembly machine in KIVA 1 at LANL had previously been performed and documented as publicly distributed benchmarks in NEA/NSC/DOC(95)03/II Volume II as HEU-COMP-INTER-003 [4].

The data from all three of these unreflected experiments should be acceptable for completing ICSBEP benchmark subcritical experiments once the uncertainty analysis, calculations, and required documentation are completed. More information for the uncertainty analysis can be obtained from HEUCOMP-INTER-003.

\subsection{SUBCRITICAL BENCHMARKING FOR SUBCRITICAL HYDRIDE CYLINDERS}

Two directly measured quantities and one inferred quantity, the neutron multiplication factor $\mathrm{k}_{\text {eff }}$, can be used to verify calculational methods. The directly measured quantities in these measurements are the auto and cross power spectral densities (frequency analysis functions) The auto power spectral density is the Fourier transform of the time distributions of counts in a detector with respect to a previous count in the same detector, which is equivalent to a one-detector Rossi- $\alpha$ in the time domain. The cross power spectral density is the Fourier transform of the time distribution of counts in one detector with respect to measurements in another detector, which is equivalent to a two-detector Rossi- $\alpha$ measurement in the time domain. If the count in one detector is measured with respect to an event in a time-tagged $\mathrm{Cf}$ source, this is a randomly pulsed neutron measurement in the time domain. Time tagging of neutron emission is accomplished by locating the ${ }^{252} \mathrm{Cf}$ isotope on one plate of a parallel plate ionization chamber and the electrical pulse produced by the spontaneous fission produced from ${ }^{252} \mathrm{Cf}$ signals the emission of prompt 
neutron from ${ }^{252} \mathrm{Cf}$ fission. Because these measurements were performed with frequency analysis techniques, the Fourier transforms of the auto- and cross-correlation functions were measured. These could be transformed back to the time domain, but that is not necessary. For a system with a source and two detectors, the measured quantities are the auto power spectral density function of the source (s) and two detectors ( 1 and 2 ): $\mathrm{G}_{\mathrm{SS}}, \mathrm{G}_{11}$, and $\mathrm{G}_{22}$ and the cross power spectral functions: $\mathrm{G}_{\mathrm{S} 1}, \mathrm{G}_{\mathrm{S} 2}$, and $\mathrm{G}_{12}$. The $\mathrm{G}$ functions are designated as auto- and cross power spectral densities (APSDs and CPSDs, respectively). These functions are directly calculated by present Monte Carlo methods such as MCNP-PoliMi [5]. Examples of these auto and cross power spectral, and other relevant frequency analysis functions are given in Appendix A.

\subsubsection{Prompt neutron decay constant}

The prompt neutron decay constant $(\alpha)$ can usually be obtained from simultaneously fitting the APSDs and CPSDs. This constant is the quantity, $\alpha$, which is obtained from Rossi- $\alpha$ or pulsed neutron measurements. The prompt neutron decay constant is very dependent on the neutron energy spectrum in the assembly and is greatly affected by the presence of hydrogen. It can be directly calculated by a variety of calculation methods, including both Monte Carlo and $\mathrm{S}_{\mathrm{n}}$ transport theory methods. In measuring the prompt neutron decay constant in frequency domain measurements, the frequency response of the detection systems must be higher than that of the fissile assembly and is usually corrected for by normalization. This normalization is usually obtained from measurements with the $\mathrm{Cf}$ source between the two detectors, all in air and away from walls and floor. If a measurement at delayed criticality is available (not for these measurements), the $\mathrm{k}_{\text {eff }}$ can be inferred. This method is known as the break frequency noise analysis method [6]. Typical data for the $\sim 16 \mathrm{~cm}$ high configuration of uranium hydride are given in Appendix A.

\subsubsection{Ratio of spectral densities}

This quantity designated as the ratio of spectral densities is formed from APSDs and CPSDs [1]. This ratio was developed to avoid some of the problems of neutron multiplication measurements (i.e., the dependence on neutron source effectiveness and detection efficiency, which both vary with fissile material as it is increased in approach to critical experiments). This ratio is the product of a complex conjugate of the cross power spectral density between detector 1 and the source $\left(\mathrm{G}_{\mathrm{S} 1}{ }^{*}\right)$ and the crosspower spectral density between detector 2 and the source, $\left(\mathrm{G}_{\mathrm{S} 2}\right)$ divided by the product of the auto power spectral density of the source $\left(\mathrm{G}_{\mathrm{SS}}\right)$ and the cross correlation between the two-detector $\mathrm{G}_{12}$ or $\mathrm{G}_{\mathrm{S} 1} * \mathrm{G}_{\mathrm{S} 2} / \mathrm{G}_{\mathrm{SS}} / \mathrm{G}_{12}$. The source effectiveness and the detection efficiencies of both detectors appear in both the numerator and denominator and thus cancel, thereby removing the dependence on source effectiveness and detection efficiencies. This ratio has been shown to be directly proportional to (1$\mathrm{k}_{\text {eff }} / \mathrm{k}_{\text {eff. }}$. This ratio can be calculated by Monte Carlo methods that properly calculate $\mathrm{G}_{12}$ by including details of the fission process that were not in Monte Carlo codes before 1991 These details were first incorporated in a Monte Carlo neutron transport code (KENO-NR) by Ed Ficaro in his PhD dissertation at the University of Michigan in 1991 [7].

\subsubsection{Inferred $k_{\text {eff }}$}

The ratio of spectral densities has been the basis of the CSDNA method for determining subcritical neutron multiplication factors. The parameters required to obtain the neutron multiplication factor from the ratio are known or measured quantities or ratios of similar quantities that can be measured. Lacking measurements, they can be calculated. Ratios can usually be measured or calculated more accurately than absolute quantities. Two subcritical measurements by the CSDNA method have been documented in the literature as NEA benchmarks: SUB-HEU-SOL-THERM-001 and SUB-HEU-SOL-THERM-002 [8]. 
This methodology to infer $\mathrm{k}_{\text {eff }}$ has more uncertainty than direct calculation of the ratio of spectral densities because of the uncertainty of the parameters needed for the interpretation to infer $\mathrm{k}_{\text {eff. }}$. However, inferred methodology has been very useful for a wide variety of applications.

\subsection{DESCRIPTION OF EXPERIMENTAL MATERIALS AND CONFIGURATIONS}

\subsubsection{Configuration of hydride cans}

The information in this section is from HEU-COMP-INTER-003 [4]. The configuration comprises 6 nominally $15.1 \mathrm{~cm}$ diameter uranium hydride cylinders in thin stainless-steel cans, 4 of which are $\sim 3 \mathrm{~cm}$ thick and 2 are $\sim 2 \mathrm{~cm}$ thick [4]. The uranium hydride cans, aluminum spacers and stainless steel fillers are described in Figures 1 and 2. The cylindrical hydride disks are canned in 0.010-in.-thick $0.0254-\mathrm{cm}$. thick) stainless steel. Each can has a $0.15875 \mathrm{~cm}$ high lip at the top to facilitate a welded seal for the lid of the can. This results in a void above the can lid that was filled with stainless-steel fillers for proper stacking alignment. The dimensional details of the canned uranium hydride, including gaps are given in Figure 3. The $2 \mathrm{~cm}$ can height (including the lip) is $2.20955 \mathrm{~cm}$, and the $3 \mathrm{~cm}$ can height (including the lip) is $3.20955 \mathrm{~cm}$. The as-built height of the assemblies of stacked cylindrical cans were not measured. The outer diameters of the uranium hydride and that of the cans were the same and the uranium hydride height varied. The stainless-steel filler was used between cans to facilitate stacking. The thickness of the cans from Reference 4 is not the same for can A and can B as it is for the other four cans. This is not possible because the can bottoms and sides were pressed from 0.010 -in.-thick stainless-steel so the bottom, sides and lids of the can must be the same like it is for the $\sim 3$-cm.-high cans.

The dimension given are not directly from dimensional analysis inspection reports at the Y-12 National Security Complex (NSC) because these Y-12 NSC dimensional analysis reports are given in inches. 


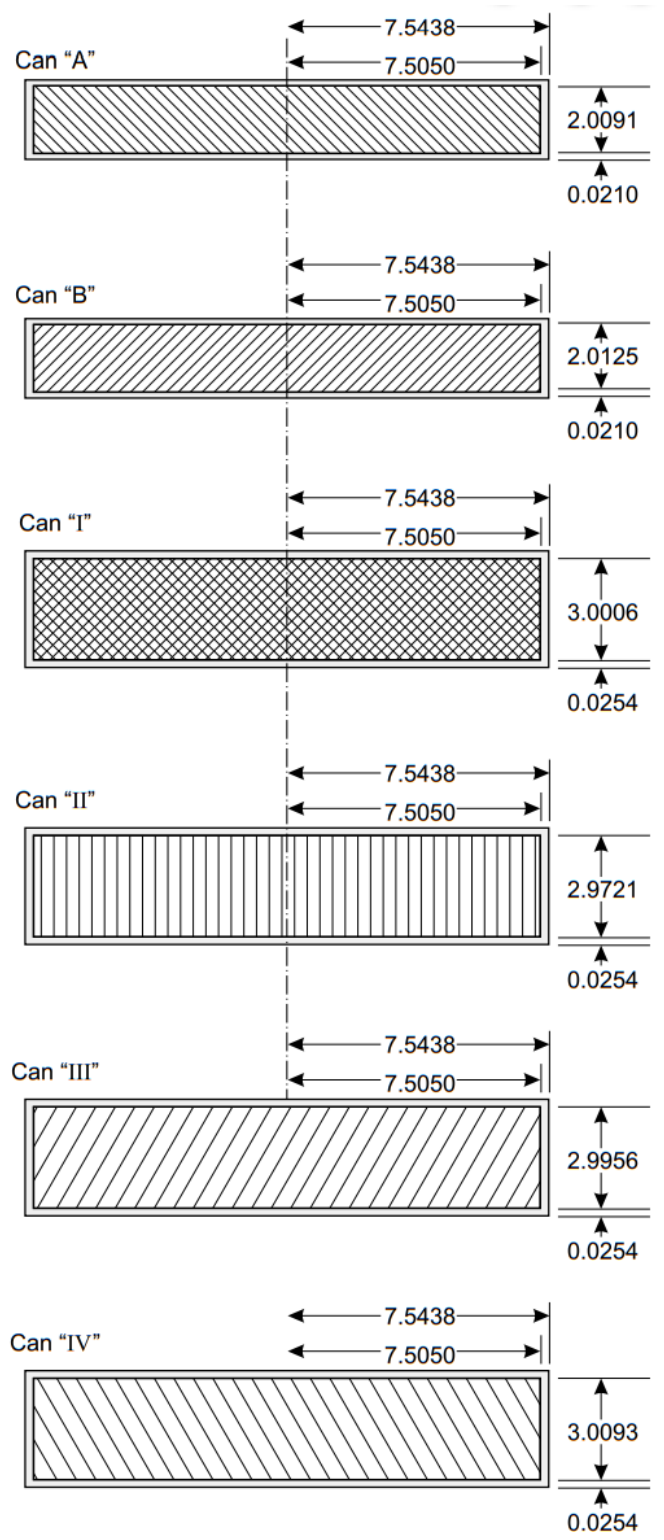

Figure 1. Description of the six uranium hydride cans from HEU-COMP-INTER-003. (All dimensions are in centimeters; steel filler not on same scale as can sketches; the outside radius of the can is $7.5438 \mathrm{~cm}$ and the radius of the uranium hydride is $7.5304 \mathrm{~cm}$.) 
From another section of reference 4 the radial air gap between the uranium hydride and the steel can is given as $0.0134 \mathrm{~cm}$ giving a radial wall thickness is $0.0254 \mathrm{~nm}$ or 10 mils thick. So the cans I, II, III, \& IV are made from 10-mils-thick stainless-steel sheets. This is consistent with the width of the lip on the cans from welding indicated on Figure 3. The thickness of the cans for parts A and B of $0.021 \mathrm{~cm}$ from reference 4 is an error and it is $0.0254 \mathrm{~cm}$ and the height of these cans is the hydride height plus the $0.0254 \mathrm{~cm}$ of each lid or $2.0599 \mathrm{~cm}$. for can A and $2.0635 \mathrm{~cm}$. for can B.

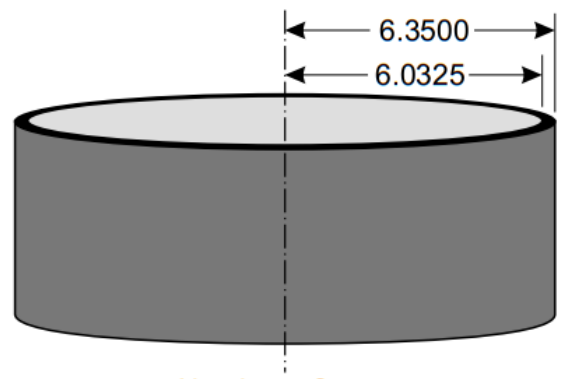

Aluminum Spacer

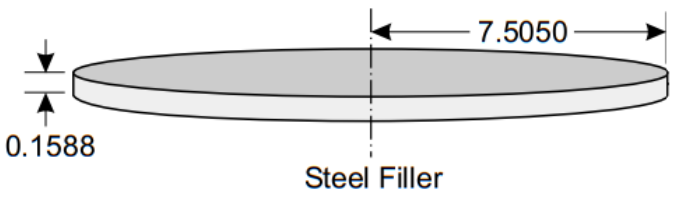

Figure 2. Description of the aluminum spacer and steel filler to aid in stacking the cans from HEU-COMP-

INTER-003. (All dimensions are in centimeters; steel filler not on same scale as spacer. Aluminum spacers were used to support the detectors and cylindrical configurations of the cans on the carbon steel table.)

In Figure 2 the radius of the stainless-steel filler is such that it would not fit inside the lip on the stainlesssteel lid shown in Figure 3. It must be smaller than $7.538 \mathrm{~cm}$ minus $0.0508 \mathrm{~cm}$.

In Figure 3, a more detailed, not-to-scale sketch of a hydride can and the steel filler depicts the welded upper section, including any air gaps, which should be used for modeling. The stainless steel filler facilitated the stacking of the hydride cans in the assembly. The steel filler radius is not consistent with the fact that the filler fits inside the lip of the welded can. The largest radius it could be is $7.4842 \mathrm{~cm}$. 


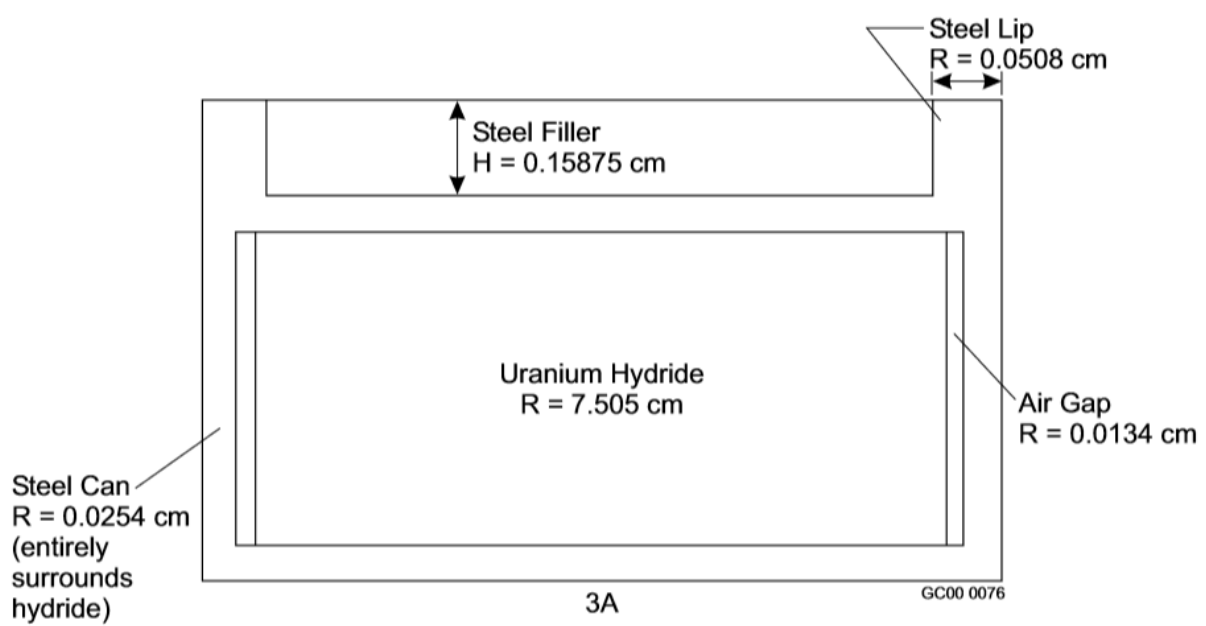

Figure 3. Schematic of the stainless steel can (not to scale, from HEU-COMP-INTER-003).

\subsubsection{Description of the californium ionization chamber}

The CSDNA method requires the use of a ${ }^{252} \mathrm{Cf}$ source contained within a small ionization chamber (also referred to as source capsule) and additional detectors mounted close to the assembly to be measured. The source ionization chamber, shown in Figure 4, was on the end of a cable that was connected to the highgain fast amplifier located at enough distance to have a negligible effect on the reactivity of the hydride assembly. The neutron source was a double-walled, parallel-plate, stainless-steel ionization chamber. The dimensions are specified on ORNL drawing Q-6252-1. The major source components were a nickel electrode, a copper conducting tube, a ceramic (silica) insulator, a copper fill tube, an inner stainless (304) steel ring, an inner stainless steel (304) chamber, a stainless steel (304) end cap, a plastic insulator (polyethylene), and an outer stainless steel (304) chamber. The inner ring and the walls of the source chamber were composed of stainless steel 304. The electrode plate was mounted to the copper fill tube, as shown in Figure 4. A more detailed Monte Carlo sketch of the californium ionization chamber used for modeling from SUB-HEU-SOL-THERM-002 [8] is given in Appendix B. The electrode was positioned $0.1 \mathrm{~cm}$ from the thin platinum foil located on the bottom of the chamber that was held in place by the inner stainless steel ring. For the configurations measured in this evaluation, the ionization chamber was placed adjacent to the top surface of the uppermost uranium hydride can in the center of the configuration and coaxially with the cylindrical assembly. The chamber was oriented as shown in Figure 4 so that the ${ }^{252} \mathrm{Cf}$, which was plated on the inner lower surface of the chamber, was approximately adjacent to the center of the upper uranium hydride can surface. Experiments were performed using a $2.6 \mu \mathrm{g}{ }^{252} \mathrm{Cf}$ source with spontaneous fission rates of $\sim 1.6 \times 10^{6}$ fissions/s. 


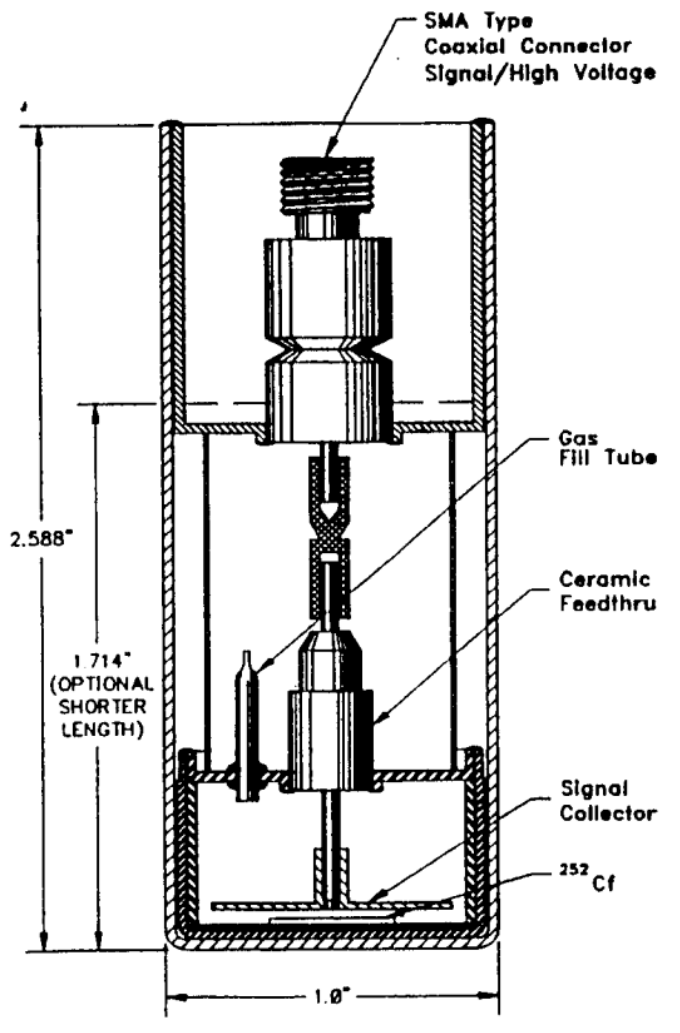

Figure 4. Sketch of the californium ionization chamber (californium deposit not to scale).

\subsubsection{Description of the detectors (mostly from SUB-HEU-SOL-THERM-002)}

The CSDNA method requires two detectors. The detectors were composite lithium-glass/organic plastic scintillation detectors that had sensitivity to fast neutrons caused by proton-recoil interactions in the organic material (to slow neutrons from the fissile assembly by interactions with the ${ }^{6} \mathrm{Li}$ ) and to gamma rays caused by interactions in both scintillator materials. The detectors were located about $6.35 \mathrm{~cm}$ from the radial surface for all three configurations. For the $\sim 11 \mathrm{~cm}$ high cylinder assembly, the top horizontal surface of the detectors was $3 / 4$ in. below the top surface of the top can and parallel to the surface of the can. For the $\sim 14$ and $\sim 16 \mathrm{~cm}$ high assemblies, the detectors were centered vertically. The detectors were supported off the table with aluminum spacers. The detectors should be included in any calculations because they reflected some leakage neutrons back into the uranium hydride assemblies. This location of detectors minimized source neutrons from the source directly to the detectors. The detectors were angularly separated by 180 degrees with respect to the axis of the cylindrical can configuration and were horizontal as depicted in Figure 5. Each detector consisted of 0.70-cm.-thick ${ }^{6} \mathrm{Li}$-enriched glass (NE-908) optically coupled to a 10.2-cm.-thick organic BICRON-420 (BC-420) scintillator mounted on a photomultiplier tube (PMT). Both the lithium glass and the organic scintillator were $9.5 \times 9.5 \mathrm{~cm}^{2}$ and were enclosed in an aluminum can $0.32 \mathrm{~cm}$ thick and $10.2 \times 10.2 \mathrm{~cm}^{2}$. The BC-420 scintillator was 
optically coupled to the PMT through a borosilicate glass faceplate. The dimensions and exact materials of the faceplate, the PMT, and the detector base were not known. A simplified sketch of the detector and a drawing of the similarly documented detector design discussed previously are shown in Figure 5. A Monte Carlo model of this detector in available in an appendix of reference 8. The faceplate was curved as shown in Figure 6. The presence of the lithium glass on the front face of the detectors reduced the reflection effects of the detectors by absorbing the reflected neutrons and must be included in any calculations. Reflected neutrons have a lower energy, and ${ }^{6} \mathrm{Li}$ has a high neutron cross section for lowenergy neutrons. In the detector, a neutron could be counted twice by scattering in the plastic and absorption in the lithium glass scintillator. Two identical detectors were used in these experiments, and they were on the opposite side of the cylindrical assembly.

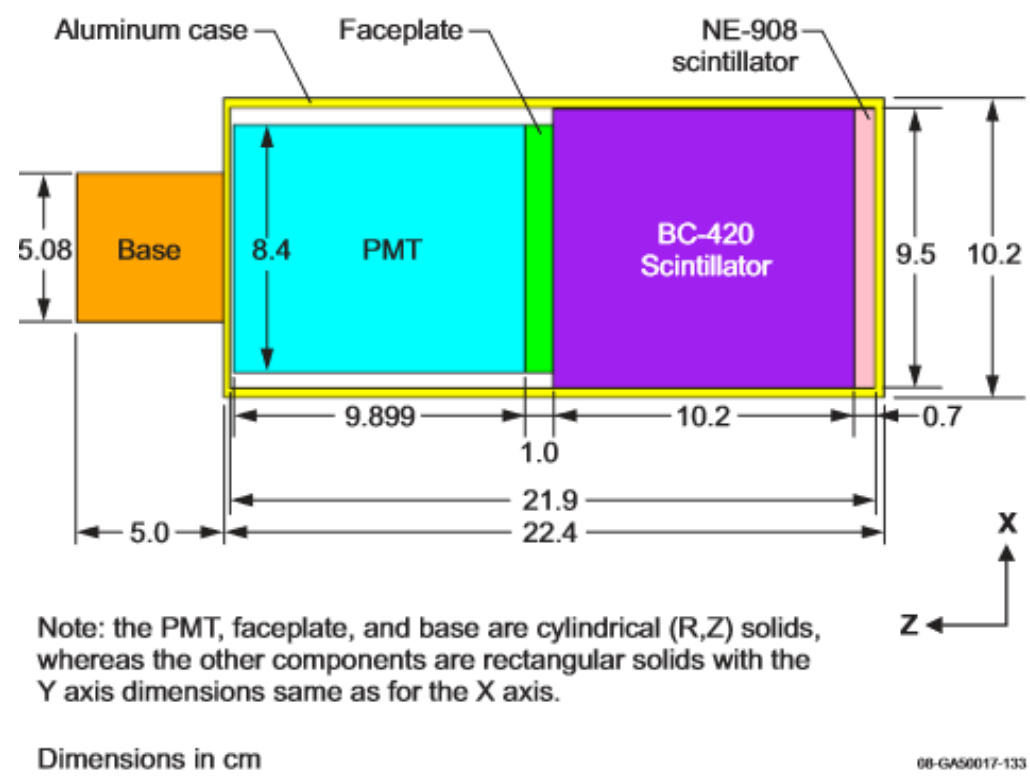

Figure 5. Detailed model of the detectors (from SUB-HEU-SOL-THERM-002). 


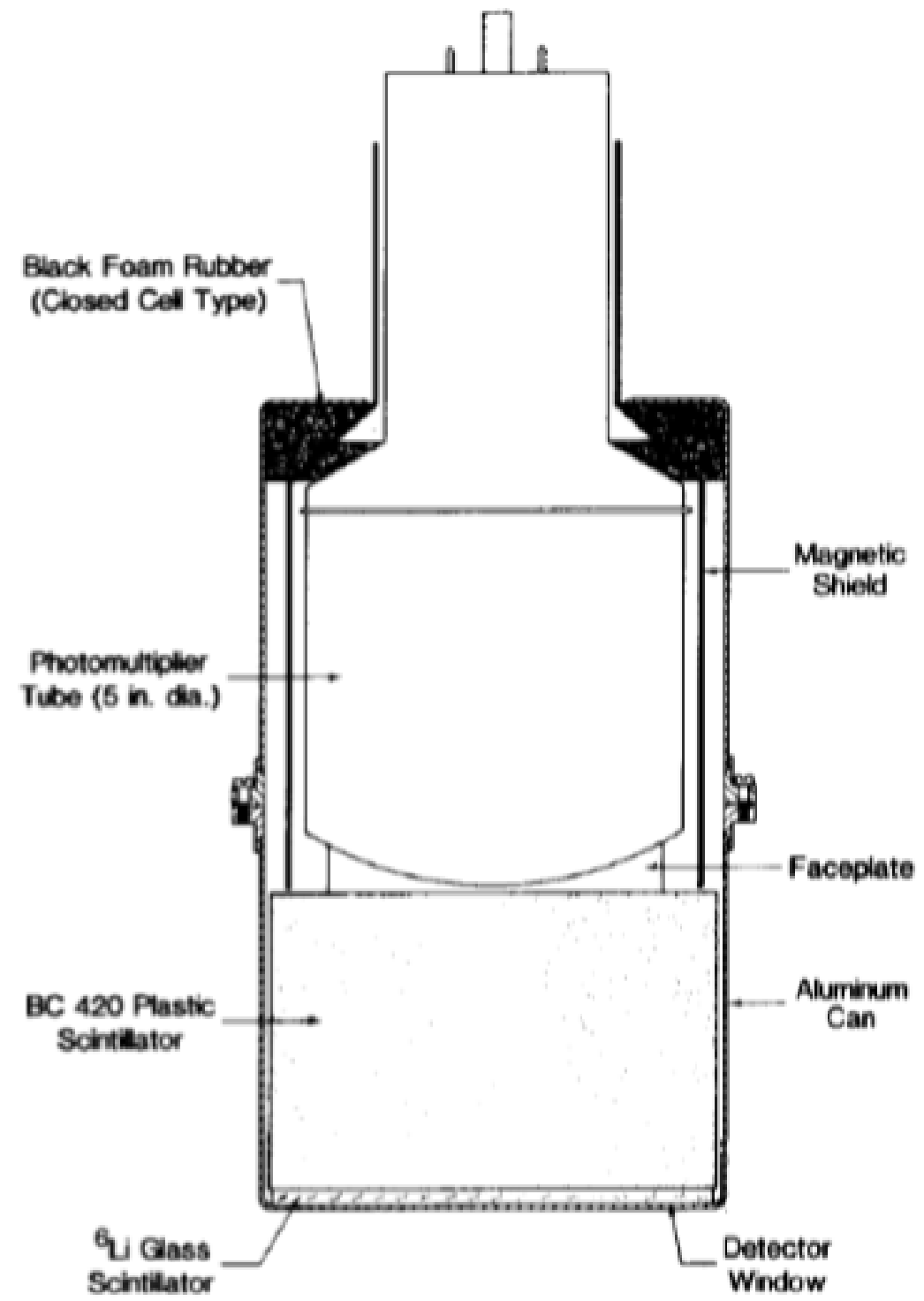

Figure 6. Composite scintillator configuration (from SUB-HEU-SOL-THERM-002).

An additional sketch of the cross section of the detectors is shown in Figure 6 and more realistically shows the detector configuration simplified in Figure 5. The differences between Figures 5 and 6 should not significantly affect the modeling calculations because of the distance the PMTs are from the uranium hydride material and the plastic scintillator in between the PMT and the uranium hydride. 
These detectors were not designed for these experiments but for the experiments for Westinghouse Idaho Nuclear Company storage tanks [8]. These uranium hydride experiments were a target of opportunity while ORNL staff was at LANL. The size of the detectors and time constraints limited these hydride experiments to configurations with $11 \mathrm{~cm}$ height or larger. This resulted in the assemblies being larger than the height $(\sim 10 \mathrm{~cm})$ of the detectors so that the detectors could be located appropriately to prevent neutrons from the source have a direct path to the detectors. The detectors were not shielded with lead. Recent Monte Carlo simulation of these detectors with fission sources at the University of Michigan have shown that about $70 \%$ of the coincidences involve only one or no neutrons. Most coincidences involve two gamma rays and one gamma ray and one neutron [9].

\subsection{DESCRIPTION OF THE MATERIAL (FROM HEU-COMP-INTER-003)}

The compositions of the six cans of uranium hydride are given in Tables 1 and 1.a. The values given in Table 1 are from analyses performed at Oak Ridge, Tennessee, which supplied LANL with the cans of uranium hydride. Table 1.a contains data from LANL.

Table 1. Oak Ridge Uranium hydride data from Reference 4

\begin{tabular}{|c|c|c|c|c|c|c|c|}
\hline $\begin{array}{c}\text { Can } \\
\text { number }\end{array}$ & Part number ${ }^{a}$ & $\begin{array}{l}\text { Density } \\
(\mathrm{g} / \mathrm{cm} 3)\end{array}$ & $\begin{array}{c}\text { Oxygen } \\
\text { (ppm) }\end{array}$ & $\begin{array}{c}\text { Nitrogen } \\
\text { (ppm) }\end{array}$ & $\begin{array}{c}\text { Carbon } \\
\text { (ppm) }\end{array}$ & $\begin{array}{c}\text { Hydrogen } \\
\text { (ppm) }\end{array}$ & $\begin{array}{c}\text { Total } \\
\text { metallic } \\
\text { (ppm) }\end{array}$ \\
\hline I & $3199-19-4481(6625)$ & 10.12 & 2,246 & 3,124 & 287 & 12,217 & 336.1 \\
\hline II & $3199-20-4487$ (6626) & 10.07 & 1,496 & 445 & 394 & 12,531 & 352.4 \\
\hline III & $3199-18-4499$ (6627) & 10.13 & 1,270 & 474 & 301 & 11,551 & 949.0 \\
\hline A & $3287-39-2340(6628)$ & 9.90 & not given & not given & 195 & not given & 841.7 \\
\hline $\mathrm{B}$ & $3287-40-8815(6631)$ & 9.86 & 1,330 & 543 & 259 & 12,432 & 636.8 \\
\hline IV & $3199-21-4504$ (6633) & 9.87 & 1,715 & 575 & 314 & 12,332 & 191.8 \\
\hline
\end{tabular}

\begin{tabular}{|c|c|c|c|c|r|r|}
\hline $\begin{array}{c}\text { Can } \\
\text { number }\end{array}$ & Part number & $\begin{array}{c}\text { High Z } \\
\text { (wt. \%) }\end{array}$ & $\begin{array}{c}{ }^{\mathbf{2 3 4}} \mathbf{U} \\
(\mathbf{w t .} \%)\end{array}$ & $\begin{array}{c}{ }^{\mathbf{2 3 5}} \mathbf{U} \\
\text { (wt. \%) }\end{array}$ & $\begin{array}{c}\mathbf{2 3 6}^{\mathbf{2}} \mathbf{U} \\
\text { (wt. \%) }\end{array}$ & $\begin{array}{c}\text { 238} \mathbf{U} \\
\text { (wt. \%) }\end{array}$ \\
\hline I & $3199-19-4481(6625)$ & 1.2115 & 0.9708 & 90.4406 & 0.4271 & 5.2423 \\
\hline II & $3199-20-4487(6626)$ & 1.1745 & 0.9835 & 90.7289 b & 0.4187 & 5.2487 \\
\hline III & $3199-18-4499(6627)$ & 1.0901 & 0.9841 & 90.7361 & 0.4190 & 5.3007 \\
\hline A & $3287-39-2340(6628)$ & 1.0851 & 0.9643 & 90.7963 & 0.3993 & 5.2401 \\
\hline B & $3287-40-8815(6631)$ & 1.0916 & 0.9943 & 90.8514 & 0.3997 & 5.2347 \\
\hline IV & $3199-21-4504(6633)$ & 1.1382 & 0.9794 & 90.7085 & 0.4128 & 5.2533 \\
\hline
\end{tabular}

aPart numbers are Y-12 NSC part numbers and four digits in parentheses are associated with the parts at LANL.

${ }^{\mathrm{b}}$ Includes $0.01 \mathrm{wt} \%{ }^{233} \mathrm{U}$. In reference 4 it states that the isotopics for uranium hydride have a larger uncertainty than for uranium metal (e.g. \pm 0.005 for ${ }^{235} \mathrm{U}$ ). According to a personal communication from Alan Moore of the Y-12 National Security Complex (May 2021) the ${ }^{235} \mathrm{U}$ content of the hydride agrees with that from the uranium metal the hydride was made from unless there was a mistake. Reference 4 states that the $235 \mathrm{U}$ uncertainty $\pm 0.05 \mathrm{wt}$. \% whereas it is much lower. From Reference 10 , the uncertainty on any sample for ${ }^{235} \mathrm{U}$ is 0.005 wt. \%, but combined with the uncertainty of the NBS standards gives an uncertainty of 0.0176 wt. \% for $235 \mathrm{U}$. Combined uncertainties for the other isotopes are: 0.0017 for ${ }^{234} \mathrm{U},{ }^{236} \mathrm{U}, 0.0130$ for ${ }^{236} \mathrm{U}$ and 0.0198 for ${ }^{238} \mathrm{U}$. 
Table 1.a. Los Alamos National Laboratory specifications for uranium hydride disks from Reference 4

\begin{tabular}{|c|c|c|c|c|c|c|}
\hline $\begin{array}{c}\text { Can } \\
\text { number }\end{array}$ & Part number & $\begin{array}{c}\text { Canned } \\
\text { Mass }^{\mathbf{b}} \\
\mathbf{( g )}\end{array}$ & $\begin{array}{c}\text { Density } \\
\left(\mathbf{g} / \mathbf{c m}^{\mathbf{3}}\right)\end{array}$ & $\begin{array}{c}\text { U } \\
(\mathbf{w t} \text { \%) }\end{array}$ & $\begin{array}{c}\text { H } \\
\text { (wt. \%) }\end{array}$ & $\begin{array}{c}\text { Other } \\
\text { (wt. \%) }\end{array}$ \\
\hline I & $3199-19-4481(6625)$ & 5,462 & 10.11 & 97.081 & 1.2217 & 1.6973 \\
\hline II & $3199-20-4487(6626)$ & 5,390 & 10.07 & 97.380 & 1.2531 & 1.3670 \\
\hline III & $3199-18-4499(6627)$ & 5,469 & 10.14 & 97.44 & 1.1551 & 1.4049 \\
\hline A & $3287-39-2340(6628)$ & 3,588 & 9.89 & 97.40 & 1.1883 & 1.4117 \\
\hline B & $3287-40-8815(6631)$ & 3,594 & 9.89 & 97.48 & 1.2432 & 1.2768 \\
\hline IV & $3199-21-4504(6633)$ & 5,355 & 9.88 & 97.354 & 1.2332 & 1.4128 \\
\hline
\end{tabular}

${ }^{a}$ Cans I, II, III, and IV are $3 \mathrm{~cm}$ thick cans, and cans A and B are $2 \mathrm{~cm}$ thick cans (Reference 4).

b This mass includes the steel can.

\section{EXPERIMENTAL RESULTS}

\subsection{EXPERIMENTAL CONFIGURATIONS}

Three main experimental configurations with two variations were used. Each assembly was restacked with a different uranium hydride part on the bottom. The six configurations were assembled and are described as follows. The stainless steel spacers were $0.1588 \mathrm{~cm}$ thick and were used to facilitate stacking. One spacer was above each can except for the one on the top. The configurations of the parts for each assembly are given in Figures 7 to 12 . The configuration numbers are the order in which the experiments were performed. An aluminum spacer ring separated the bottom can off the carbon steel table about $5 \mathrm{~cm}$, and the top of the steel table was $86 \mathrm{~cm}$ above the floor. The table was in the corner of

KIVA- 1 to the right of the personnel entry and $3 \mathrm{~m}$ from the two adjacent walls. The composition of the concrete was assumed as given in Appendix D. 


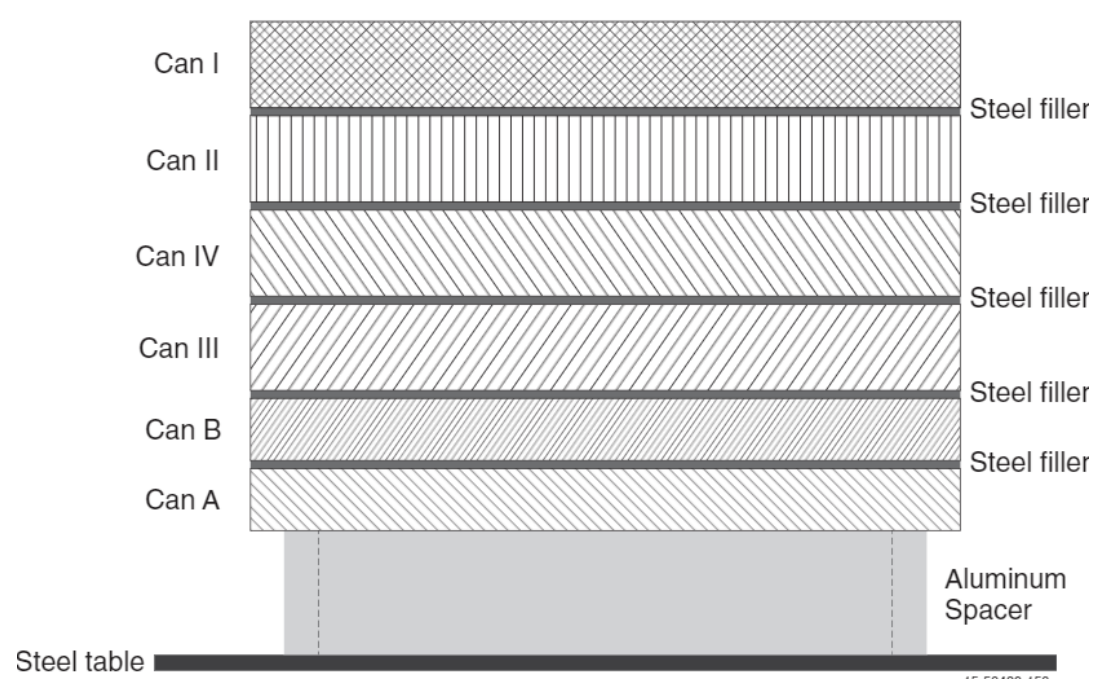

Figure 7. Sketch of Configuration 1 (not to scale).

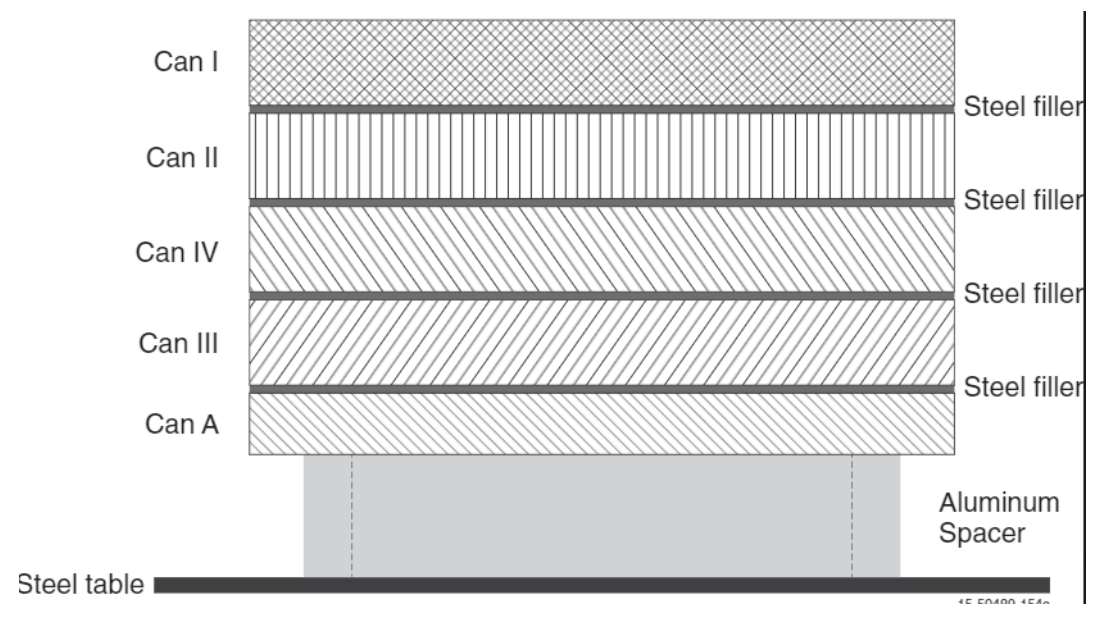

Figure 8. Sketch of Configuration 2 (not to scale). 


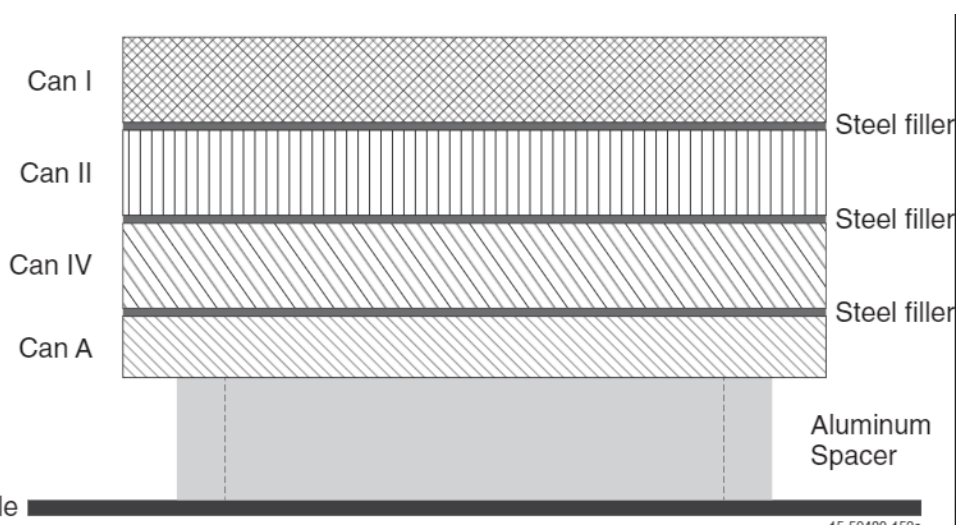

Steel table

Figure 9. Sketch of Configuration 3 (not to scale).

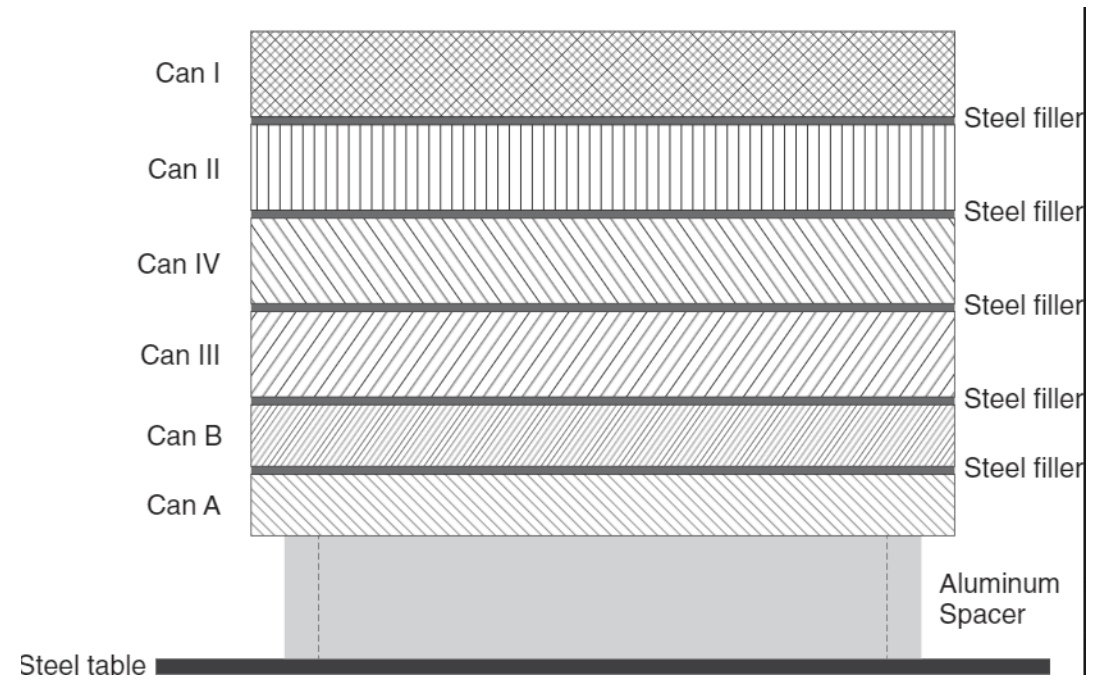

Figure 10. Sketch of Configuration 4 (not to scale). 


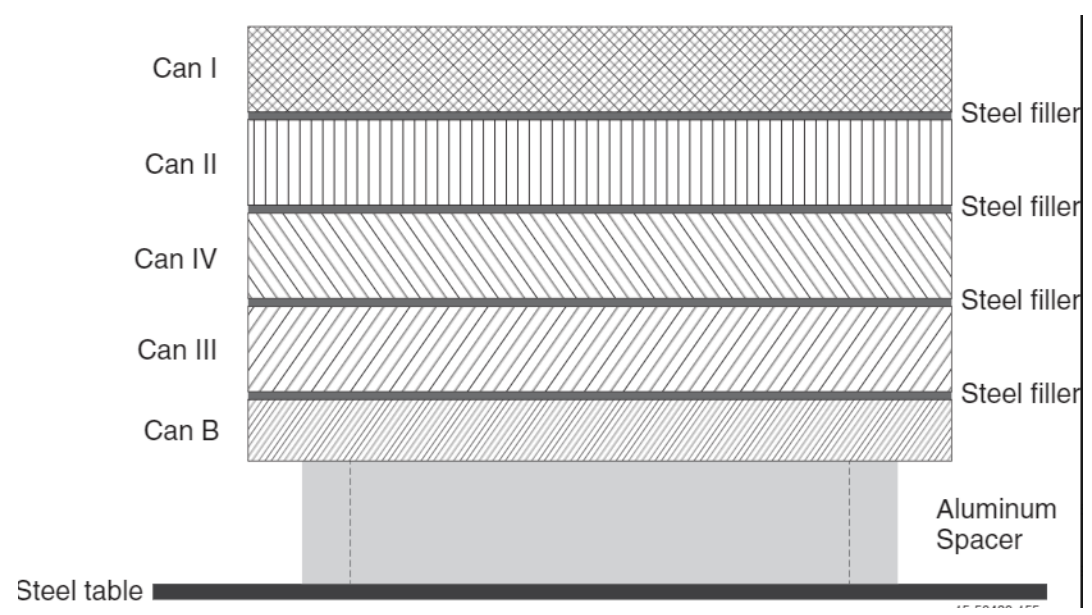

Figure 11. Sketch of Configuration 5. (Not to scale).

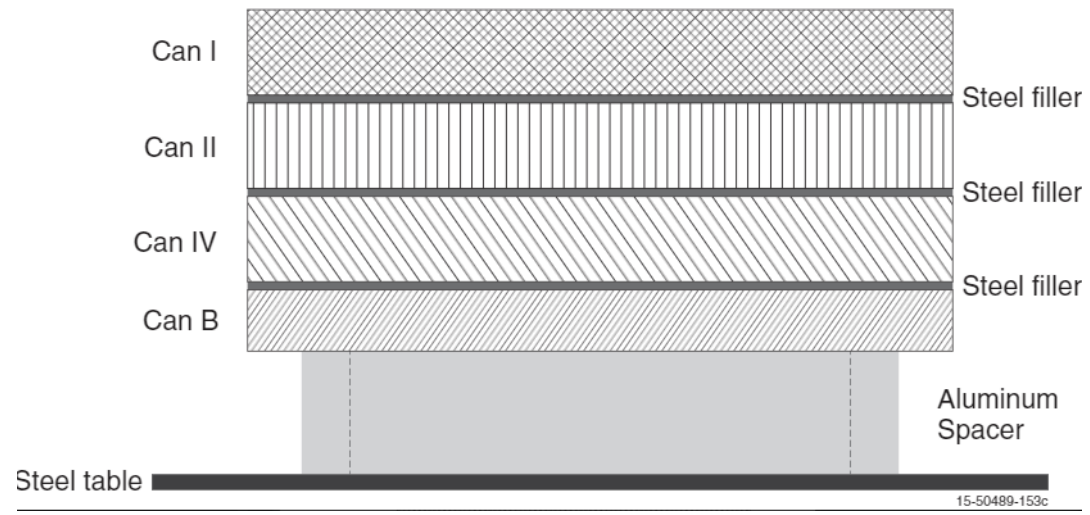

Figure 12. Sketch of Configuration 6 (not to scale).

The order of the assembly of the configurations was Configuration 1, 2, 3, 4, 5, and 6 . The first three configuration $(1,2$, and 3$)$ were assembled sequentially and CSDNA measurements performed, Then, Configurations $(4,5$, and 6$)$ were assembled sequentially. The second three configurations involved complete removal of the material from the table and restacking with a different hydride can on the bottom. Thus, the second three configurations differed from the first three by no more than $6 \mathrm{~g}$, which is the difference in mass of Can A and Can B. This was done to check reproducibility of the assembly and the measurements. Four CSDNA measurements were taken for the $11 \mathrm{~cm}$ high assembly and two each of the 14 and $16 \mathrm{~cm}$ high assemblies. Measurements at LANL of the height showed that the measured height of a stack of cans was only 0.001 inches more than the sum of the thicknesses of the cans and stainless steel fillers. The LANL conclusion was that there was negligible void between cans despite the several cans and fillers in the stack. We make the same assumption for these configurations. 


\subsection{CALIFORNIUM SOURCE DRIVEN NOISE ANALYSIS MEASUREMENTS}

The CSDNA experiments measure the Fourier transforms of the time domain cross-correlation functions between the two detectors and between the two detectors and the source emission. The latter correlation functions are the equivalent of a randomly pulsed neutron measurement in the time domain. These two Fourier transforms are designated as $\mathrm{G}_{\mathrm{S} 1}$ and $\mathrm{G}_{\mathrm{S} 2}$. The cross-correlation function of the two detectors, which is the equivalent of a two-detector Rossi- $\alpha$ measurement, is also Fourier transformed to give $\mathrm{G}_{12}$. The time distribution of counts in the source ionization chamber with respect to a previous count in the source ionization chamber is also Fourier transformed to give the APSD of the source $\mathrm{G}_{\mathrm{SS}}$. These crossand autocorrelation functions are combined in a ratio of spectral densities, $\mathrm{G}_{\mathrm{S} 1} * \mathrm{G}_{\mathrm{S} 2} /\left(\mathrm{Gss}_{12}\right)$, where * means complex conjugation. The ratio is constant at low frequencies and the averages over the frequency range where it is constant are used to obtain the neutron multiplication factor using a point kinetics model to infer the neutron multiplication factor, $\mathrm{k}_{\text {eff }}$. The CSDNA online results for measuring the ratio of spectral densities at low frequency are given in Table 2 for the six configurations. Two different point kinetics models exist for interpreting these ratios of spectral densities - a Pare/Mihalczo formulation and an Akcasu/Stolle formulation [11]. At low neutron multiplication factors $(<0.80)$, the latter formulation gives neutron multiplication factors much higher than actual. Here, both interpretations give the same result within experimental uncertainty in the measurements. Some of these differences are described in Appendix C. The uncertainties in the measured ratios for the restacked $\sim 11$ and $\sim 14 \mathrm{~cm}$ high configurations were not as accurately measured as the $\sim 16 \mathrm{~cm}$ high configurations because of time constraints for the measurements. For final analysis, these data should be re-examined to confirm the results given here.

Table 2. Measured online ratios of spectral densities for cylindrical hydride cans of various heights. (In this table, Arabic numerals are used instead of Roman numerals to identify the uranium hydride cans.)

\begin{tabular}{|c|c|c|c|c|c|}
\hline \multirow[b]{2}{*}{ Assembly ${ }^{a}$} & \multirow{2}{*}{$\begin{array}{c}\text { Nominal } \\
\text { height }^{\mathrm{b}} \\
(\mathrm{cm})\end{array}$} & \multicolumn{2}{|c|}{ Noise analysis measurement } & \multicolumn{2}{|c|}{ Ratio of spectral densities $\left(\times 10^{-4}\right)$} \\
\hline & & Identification & $\begin{array}{c}\text { Digitizing rate } \\
(\mathrm{kHz})\end{array}$ & Measured & $\begin{array}{l}\text { Corrected for } \\
\text { source effects }\end{array}$ \\
\hline $\mathrm{AB} 3421$ & $16(6)$ & $\begin{array}{l}\mathrm{AA} \\
\mathrm{AB}\end{array}$ & $\begin{array}{l}250(500) \\
300(200)\end{array}$ & $\begin{array}{l}311.1 \pm 0.6 \\
312.4 \pm 0.9\end{array}$ & $\begin{array}{l}366 \pm 1 \\
368 \pm 1\end{array}$ \\
\hline BA.3421 & $16(6)$ & $\begin{array}{l}\mathrm{AG} \\
\mathrm{AH}\end{array}$ & $\begin{array}{l}1000(14) \\
250(1600)\end{array}$ & $\begin{array}{l}302.9 \pm 2.0 \\
317.4 \pm 0.9\end{array}$ & $\begin{array}{l}358 \pm 2 \\
375_{ \pm 1}\end{array}$ \\
\hline $\begin{array}{l}\text { A3421 } \\
\text { B3421 }\end{array}$ & $\begin{array}{l}14(5) \\
14(5)\end{array}$ & $\begin{array}{l}\text { AC } \\
\text { AJ }\end{array}$ & $\begin{array}{l}250(500) \\
1000(23)\end{array}$ & $\begin{array}{l}501.7 \pm 1.0 \\
514.6 \pm 11.5\end{array}$ & $\begin{array}{l}590 \pm 1 \\
612 \pm 12\end{array}$ \\
\hline $\begin{array}{l}\text { A421 } \\
\text { B421 }\end{array}$ & $\begin{array}{l}11(4) \\
11(4)\end{array}$ & $\begin{array}{l}\mathrm{AD} \\
\mathrm{AK}\end{array}$ & $\begin{array}{l}250(500) \\
1000(15)\end{array}$ & $\begin{array}{l}1026 \pm 2 \\
1033 \pm 11\end{array}$ & $\begin{array}{l}1209 \pm 2 \\
1228 \pm 13\end{array}$ \\
\hline
\end{tabular}

${ }^{a}$ The cylindrical cans are identified in this table by the numbers A, B, 1, 2, 3, and 4 . The letters and numbers given are in the order of the can stack, bottom to top. The cans identified by letters had a hydride thickness of $\sim 2 \mathrm{~cm}$, and those with numbers had a hydride thickness of $\sim 3 \mathrm{~cm}$.

${ }^{\mathrm{b}}$ These values are nominal hydride heights. The numbers in parentheses are the number of uranium hydride cans in the assembly.

${ }^{c}$ The values for these parentheses are the number of 512 data blocks sampled in thousands.

${ }^{\mathrm{d}}$ This is a linear correction based on the fraction of californium fission not counted in the californium fission detection system. Uncertainties are one standard deviation of the mean. 
The $\mathrm{k}_{\text {eff }}$ values inferred from the ratios of spectral densities in 1989 are given in Table 3. The various quantities required by the point kinetics models to infer the neutron multiplication factor were obtained from calculation and measured parameters of californium fission. The uncertainties given do not include uncertainties in the calculated parameter for interpreting the ratios. The $\mathrm{k}_{\text {eff }}$ values inferred with the Akcasu/Stolle formulation are: 0.944, 0.922, and 0.878. The values obtained from the Pare/Mihalczo formulation of point kinetics are: $0.943 \pm 0.002,0.917 \pm 0.003$ and $0.867 \pm 0.004$ for hydride heights of $\sim 16, \sim 14$, and $\sim 11$, respectively. Other measurement interpretations have shown that at these high $\mathrm{k}_{\text {eff }}$ values, both formulations predict the same values. The neutron multiplication factors calculated in 1990 using the MCNP code [12] with ENDF/B-V (point cross sections), the KENO code [13] with ENDF/B-IV (27 group cross sections), and the Hansen Roach (16 group cross sections) [14] varied by as much as $2 \%$, with those from MCNP agreeing best with the measured values. The Monte Carlo calculated values of $\mathrm{k}_{\mathrm{eff}}$ that have an uncertainty of \pm 0.005 are in good agreement with the measurements.

Table 3. Inferred neutron multiplication measurements from the CSDNA measurements

\begin{tabular}{|c|c|c|c|c|c|}
\hline \multirow[b]{4}{*}{$\begin{array}{c}\text { Nominal } \\
\text { height } \\
(\mathrm{cm})\end{array}$} & \multirow{4}{*}{$\begin{array}{l}\text { Average } \\
\text { ratios of } \\
\text { spectral } \\
\text { densities } \\
\left(\times 10^{-4}\right)\end{array}$} & \multicolumn{4}{|c|}{ Neutron multiplication factor } \\
\hline & & \multirow[b]{3}{*}{$\begin{array}{l}\text { From ratio } \\
\text { of spectral } \\
\text { densities }^{b}\end{array}$} & \multicolumn{3}{|c|}{ From calculations } \\
\hline & & & \multirow{2}{*}{$\begin{array}{c}\text { MCNP } \\
\text { ENDF/B V }\end{array}$} & \multicolumn{2}{|c|}{ KENO } \\
\hline & & & & $\begin{array}{c}\text { Hansen } \\
\text { Roach } \\
\text { (16 group) }\end{array}$ & $\begin{array}{c}\text { ENDF/B IV } \\
\text { (27 group) }\end{array}$ \\
\hline 16 & $368 \pm 10$ & $0.942 \pm 0.002$ & 0.952 & 0.955 & 0.974 \\
\hline 14 & $592 \pm 10$ & $0.917 \pm 0.003$ & 0.922 & 0.941 & 0.947 \\
\hline 11 & $1212 \pm 10$ & $0.867 \pm 0.004$ & 0.860 & 0.870 & 0.878 \\
\hline
\end{tabular}

${ }^{\text {a }}$ Weighted with the inverse of the standard deviations given in Table I. For the nominal heights of 14 and $1 . \mathrm{cm}$, the error is estimated as half the difference where only two measurements were made and half the variation for the $16-\mathrm{cm}$ nominal height.

${ }^{\text {b }}$ The neutron multiplication factors obtained, assuming that the detection process significantly affects subsequent fission chain populations, are $0.944,0.922$, and 0.878 , respectively.

${ }^{\mathrm{c}} \mathrm{MCNP}$ Monte Carlo calculations by Chancellor of the Critical Experiments Facility of Los Alamos National Laboratory. ${ }^{4}$ Calculations have $1 \sigma$ uncertainties of 0.005 .

Extrapolations to delayed critical indicate that adding a $3 \mathrm{~cm}$ can and a $2 \mathrm{~cm}$ can would result in the unreflected cylindrical system being above critical, with a critical mass pf of about $37 \mathrm{~kg}$, which is considerably less than the critical mass of an unreflected and unmoderated highly enriched uranium metal sphere. For a spherical configuration of highly enriched uranium hydride, the critical mass would be even less.

For the final analysis of these measurements, these ratios of spectral densities and inferred neutron multiplication factors must be corrected for the number of californium fissions not detected. This could be due to fission products after neutron emission not being exactly 180 degrees apart. Mattingly's higherorder statistics development [15] allowed the quantitative determination of the fraction of californium fission counted in these types of chambers and showed that $4 \%$ of the fissions were not counted. This was determined by measuring the ratio of contributions to $\mathrm{G}_{23}$ associated with the californium detection to $\mathrm{G}_{23}$, which contains contributions from undetected californium fissions. The online measurement of $\mathrm{G}_{23}$ included these undetected fissions. The ratio of spectral densities determined online must be increased by this correction to get the true values of the measured ratio of spectral densities from what is presented in this document. Using these corrected ratios will decrease the neutron multiplication factor slightly ( $4 \%$ in $(1-\mathrm{k}) / \mathrm{k})$. The ratios of spectral densities presented in this report were obtained online at the time of the 
measurements. At that time, the ability to determine the fraction of californium fission not counted was not available because the higher-order development occurred much later than these measurements with uranium hydride.

In the final benchmark analysis, the calculations must be performed with present-day calculational methods, such as present versions of MCNP [LANL trademark], MCNP-PoliMi [5], and existing neutron two-dimensional transport theory codes. Present-day cross section data must also be used.

\subsection{ROOM RETURN}

The effects of room return on the neutron multiplication factor for all three configurations should be calculated by Monte Carlo methods. The concrete block walls can be simulated for Monte Carlo calculation by 4.35 -in.-thick concrete [16].

\section{UNCERTAINTY ANALYSIS}

This uncertainty analysis should mimic that of a previous ICSBEP benchmark (HEU-COMP-INTER-003) [4]. The appropriate uncertainties from this benchmark are can height $( \pm 1 \%)$, can radial wall thickness $( \pm 1 \%),{ }^{235} \mathrm{U}$ concentration $( \pm 0.05$ wt. $\%), \mathrm{UH}_{3}$ density $(0.5 \%)$, and impurities. Others are radial alignment of parts ( $0.005 \mathrm{in}$.), thickness of stainless steel, and stainless steel filler (assumed 0 with uncertainty of +0.001 in.)

\section{CONCLUSIONS}

Californium source driven noise analysis (CSDNA) subcritical measurements were successfully performed by ORNL for stainless-steel canned, highly enriched $\left(93.15 \mathrm{wt} . \%{ }^{235} \mathrm{U}\right)$ uranium hydride unreflected cylindrical assemblies at LANL in 1989. These may be the only unreflected configurations of enriched uranium hydride ever published. The presence of hydrogen dilutes the uranium density, reducing the reactivity, but this is offset by the moderating effects of the hydrogen, which slows down neutrons, thereby increasing fission probability. The nominal hydride heights of these 7.505 -cm-hydride-radius assemblies were $\sim 11, \sim 14$ and $\sim 16 \mathrm{~cm}$ with masses of 19,795, 25,264, and $28,858 \mathrm{~g}$ (including the stainless steel cans), respectively. The neutron multiplication factors obtained from the measured ratios of spectral densities were $0.942 \pm 0.002,0.917 \pm 0.003$, and $0.867 \pm 0.004$ for uranium hydride heights of $\sim 16,14$, and $11 \mathrm{~cm}$ heights, respectively. The neutron multiplication factors calculated in 1990 using the MCNP code with ENDF/B-V (point cross sections) and the KENO code with ENDF/B-IV (27 group cross sections) and the Hansen Roach (16 group cross sections) varied by as much as $2 \%$, with those from MCNP agreeing best with the measured values. Extrapolations to delayed critical indicate that the addition of one more $3 \mathrm{~cm}$ can and one more $2 \mathrm{~cm}$ can would result in the unreflected cylindrical system being slightly above critical with a critical mass $\sim 37 \mathrm{~kg}$, which is considerably less than the critical mass of unreflected and unmoderated highly enriched uranium metal sphere. A spherical unreflected highly enriched uranium hydride sphere would have a critical mass less than $37 \mathrm{~kg}$.

The benchmarks could be performed for directly measured quantities, such as the ratio of spectral densities, prompt neutron decay constants, count rates, or neutron multiplication factors obtained from the ratio of spectral densities. Directly measured quantities will have lower uncertainties than inferred quantities because the additional parameters to interpret the measured data have uncertainties, such as the neutron multiplication factor from the CSDNA measurements.

The experimental data recorded online need to be reevaluated. This documentation of these experiments was performed to provide information so that a later date, researchers could perform the required 
uncertainty and calculational analyses and documentation to use these data for an ICSBEP or NEA benchmark. The data from the measurements are available from ORNL Records Management Services Department, and the ORNL logbook is available from John Bess at Idaho National Laboratory.

\section{ACKNOWLEDGMENTS}

ORNL acknowledges the help provided by the staff of the LANL Critical Facility Staff, particularly E. Plassman and R. Anderson, T. Chancellor for his work on calculations, and L. Petrie for the ORNL calculations. The publication of this work was supported by Douglas Bowen of the Nuclear Criticality, Radiation Transport, and Safety Section of the Nuclear Energy and Fuel Cycle Division and the Nuclear Criticality Safety Program at ORNL, which is managed by the National Nuclear Security Administration for the US Department of Energy.

\section{REFERENCES}

1. J. T. Mihalczo and V. K. Paré, "Theory of Correlation Measurement in Time and Frequency Domains with ${ }^{252}$ Cf," Ann. Nucl. Energy 2, 97-105 (1975). [OSTI \#4243449]

2. J. T. Mihalczo, V. K. Paré, and E. D. Blakeman, "The ${ }^{252}$ Cf-Source-Driven Noise Measurements of Unreflected Uranium Hydride Cylinder Subcriticality,” Trans. Am. Nucl. Soc. 63, 221 (1991).

3. E. D. Blakeman and T. E. Valentine, Unreflected High Enriched Uranyl Nitrate Subcritical Noise Measurements, SUB_HEU_SOL_THERM-001, NEA/NSC/DOC/(95)03/II Volume II (2019).

4. R. W. Brewer and Raphael LaBauve, Reflected Uranium-Hydride Cylindrical Assemblies, HEUCOMP-INTER-003, NEA/NSC/DOC(95)03/II, International Handbook of Evaluated Criticality Safety Benchmark Experiments, Volume II (2019).

5. S. A. Pozzi, E. Padovani, and M. Marseguerra, "MCNP-PoliMi: A Monte Carlo Code for Correlation Measurements," Nucl. Instrum. Methods Phys. Res., Sect. A 513, no. 3, 550-558 (2003).

6. R. E. Uhrig, Random Noise Techniques in Nuclear Reactor Systems, The Ronald Press Co. (January 1970).

7. E. P. Ficaro and D. K. Wehe, "Monte Carlo Simulation of the ${ }^{252} \mathrm{Cf}-$ Source-Driven Noise Analysis Measurement for Determining Subcriticality," Proc. Int. Topl. Mtg. Advances in Mathematical, Computations, and Reactor Physics, Pittsburgh, Pennsylvania (1991).

8. E. D. Blakeman, Subcritical Noise Measurements for Two Coaxial Cylindrical Tanks Containing 93.1 wt. \% Uranyl Nitrate Solution, SUB-HEU-SOL-THERM-002, NEA/NSC/DOC/(95)03/NSC/DOC, International Handbook of Evaluated Criticality Safety Benchmark Experiments, (2019).

9. Casio and S. Clarke, University of Michigan, personal communication (2021)

10. John T Mihalczo, :Uncertainties in Masses, Dimensions, Impurities, Isotopics of HEU Metal Used in Critical Experiments at ORCEF: ORNL/TM-2012/32, Oak Ridge National Laboratory, (September 2012) [OSTI \# 1052244]

11. A. Z. Akcasu and A. Stolle, "Langevin Equation Approach to Reactor Noise Analysis: Stochastic Transport Equation," Nucl. Sci. Eng. 113, no. 1, 31-55 (1993).

12. T. Chancellor, Los Alamos National Laboratory Critical Experiments Facility, Personal Communication (1990).

13. L. M. Petrie and N. F. Cross, KENO IV: An Improved Monte Carlo Criticality Program, ORNL-4938, Oak Ridge National Laboratory, (1975). 
14. G. E. Hansen and W. H. Roach, Six and Sixteen Group Cross Sections for Fast and Intermediate Critical Assemblies, LAMS_2543, Los Alamos Scientific Laboratory (1961).

15. J. K. Mattingly, "Multivariate high order statistics of measurements of the temporal evolution fission chain reactions," PhD dissertation in 1998 at The University of Tennessee Nuclear Engineering Department, also ORNL/TM-2001/45 (March 2001) [OSTI https://doi.org/10.2172/814036].

16. R. Sanchez, Personal communication, Los Alamos National Laboratory (2020) 



\section{APPENDIX A. FREQUENCY ANALYSIS DATA FOR THE 16 CM HIGH CONFIGURATION OF URANIUM HYDRIDE CYLINDERS}

This appendix presents typical data from the californium source-driven noise analysis date for the highly enriched uranium hydride cylinder with a nominal height of $16 \mathrm{~cm}$. The californium source detection channel is designated as channel 1 and the detection channels as channels 2 and 3. It presents the auto power spectral densities, real and imaginary parts of the cross-power spectral densities, the coherence

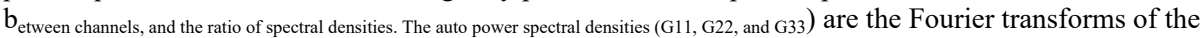
distributions of counts in a detection channel and a previous count in the same detection channel. The cross-power spectral densities $\left(\mathrm{G}_{12}, \mathrm{G}_{13}\right.$, and $\left.\mathrm{G}_{23}\right)$ are the Fourier transforms of the distributions of counts in one detector with respect to a previous count in another detector. The coherence is the following ratio: $\left(\mathrm{G}_{\mathrm{ij}}\right)^{2} /\left(\mathrm{G}_{\mathrm{ii}} \mathrm{G}_{\mathrm{jij}}\right)$. For a three-channel system, three values exist: $\left(\mathrm{G}_{12}{ }^{2} /\left(\mathrm{G}_{11} \mathrm{G}_{22}\right),\left(\mathrm{G}_{13}\right)^{2} /\left(\mathrm{G}_{11} \mathrm{G}_{33}\right)\right.$, and $\left(\mathrm{G}_{23}\right)^{2} /\left(\mathrm{G}_{22} \mathrm{G}_{33}\right)$. They are related to the signal-to-noise ratio for low coherences. The ratio of spectral densities forms as $\left(\mathrm{G}_{12} * \mathrm{G}_{13}\right) /\left(\mathrm{G}_{11} \mathrm{G}_{23}\right)$. The ratio of spectral densities was formed independent of detection efficiency and, at low frequency, is related to $\left(1-\mathrm{k}_{\mathrm{eff}}\right) / \mathrm{k}_{\mathrm{eff}}$. These frequency analysis functions are defined in Reference A.1, and the relationship between the ratio of spectral densities at low frequency and $\mathrm{k}_{\text {eff }}$ is defined in Reference A.2. Figures A.1 through A.7 show typical data from the cylindrical uranium hydride assembly with a nominal height of $16 \mathrm{~cm}$.
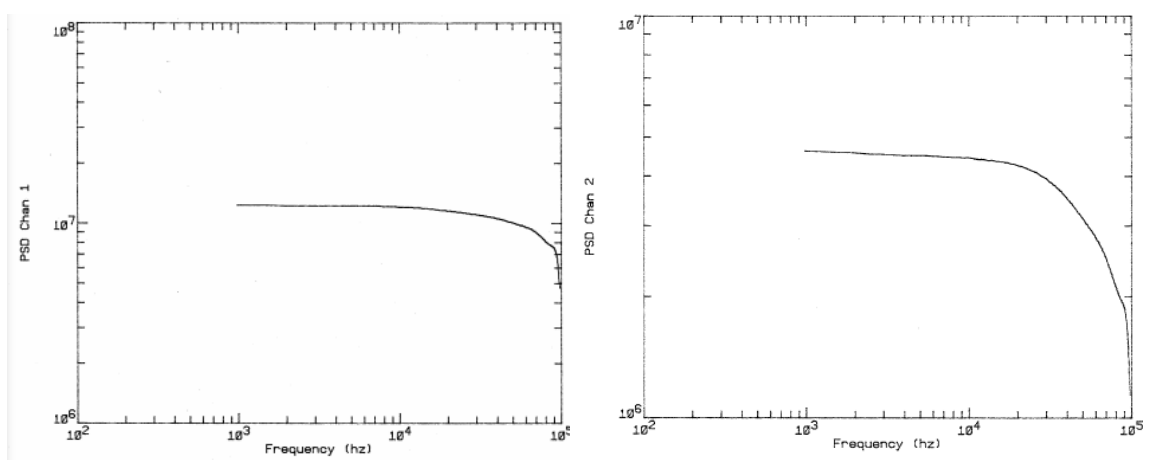

Figure A.1. Auto power spectral densities for the californium source detection channel (left $G_{11}$ or PSD 1) and the first detector (right PSD2). 

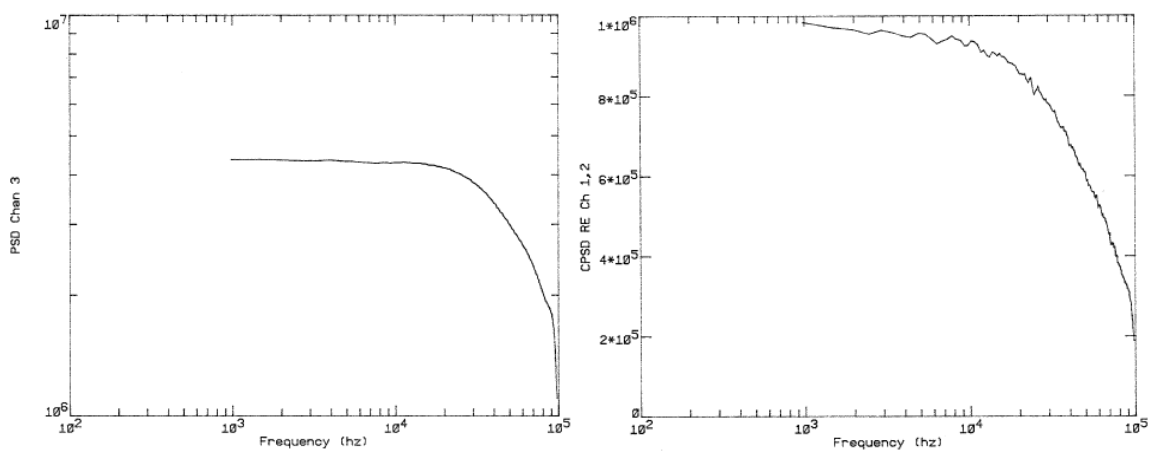

Figure A.2. Auto power spectral density for the second detector (left) and the real part of the cross-power spectral density between the first detector and the californium source (right).
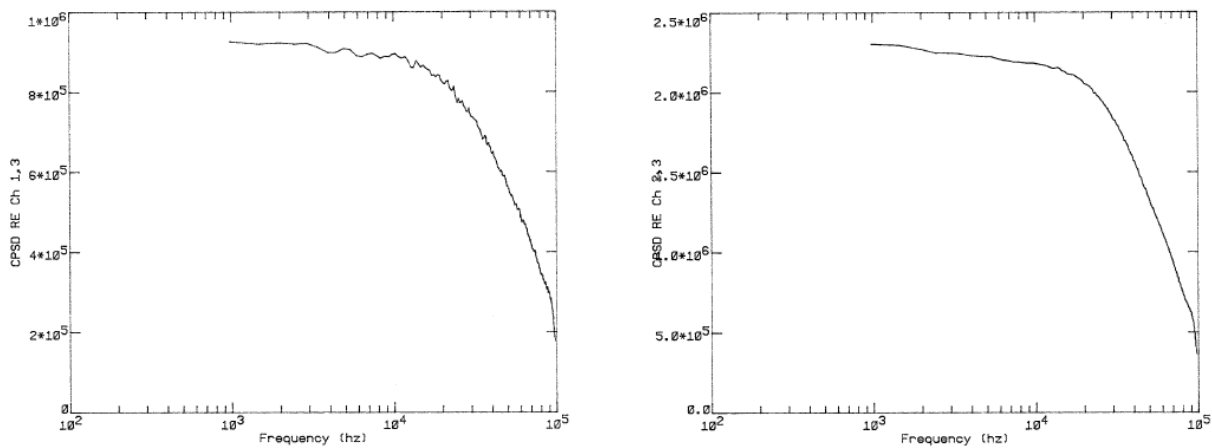

Figure A.3. Real part of the cross-power spectral density between the second detector and the californium source (left) and the real part of the cross-power spectral densities between the two detectors (right). 

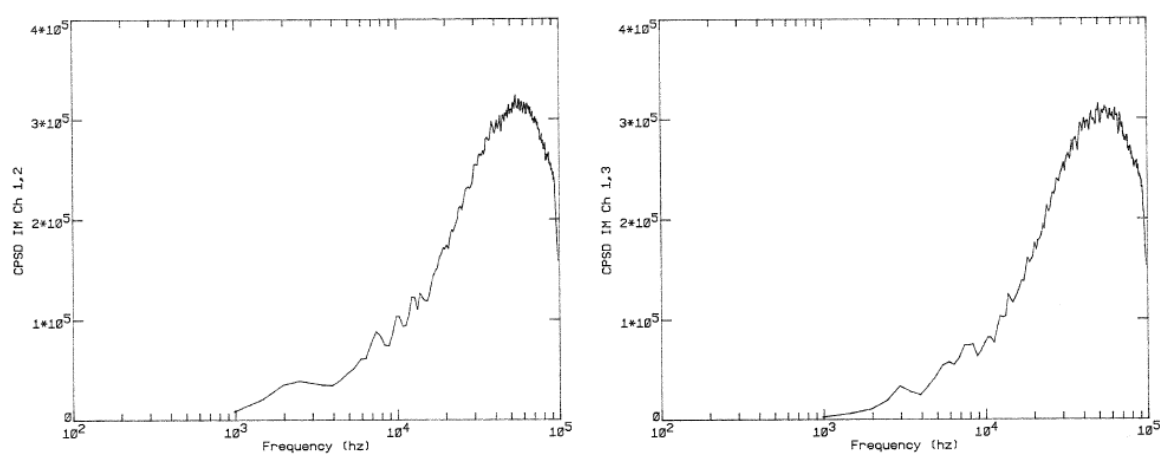

Figure A.4. Imaginary part of the cross-power spectral density between the first detector and the californium source (left) and between the second detector and the californium source (right).
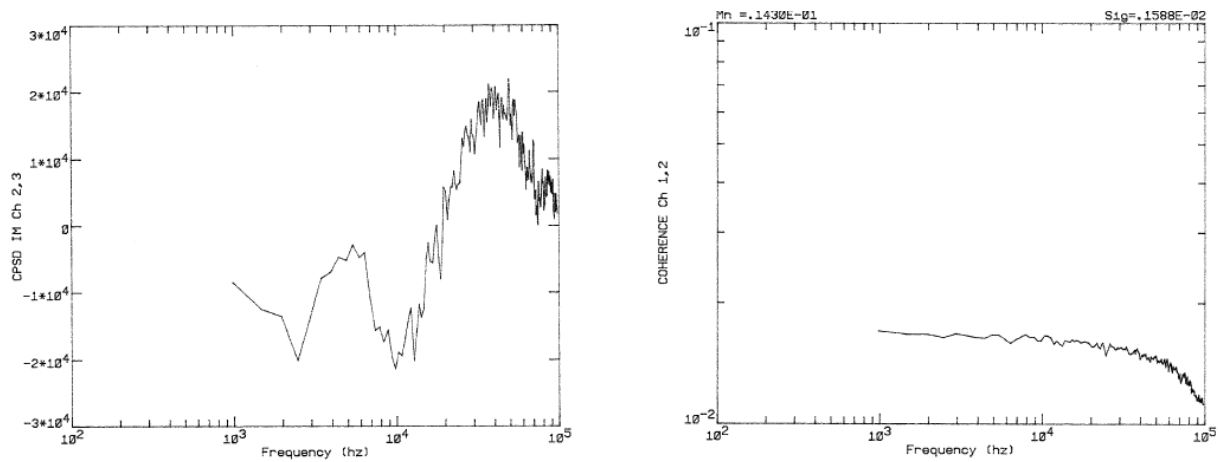

Figure A.5. Imaginary part of the cross-power spectral density between the two detectors (left) and the coherence between the first detector and the californium source (right). 

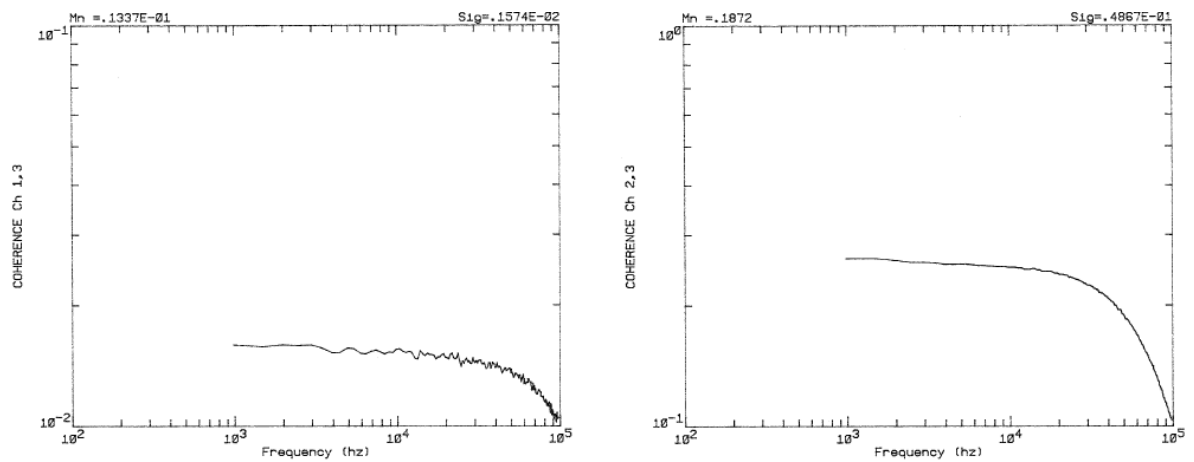

Figure A.6. Coherence between the second detector and the californium source (left) and between the two detector (right).

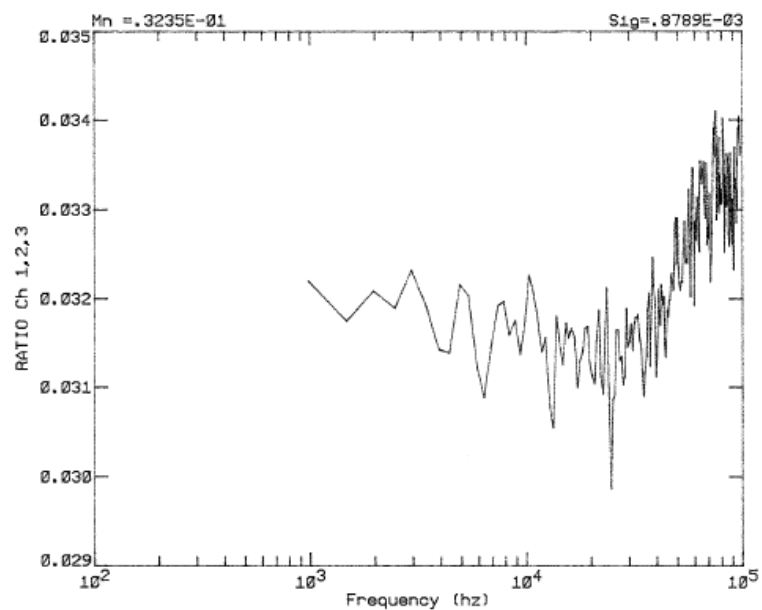

Figure A.7. Ratio of spectral densities between the californium source and the two detectors.

The auto and real and imaginary parts of the cross-power spectral densities (eight functions) can be fitted simultaneously to obtain the break frequency, which is related to the prompt neutron decay constant. These functions are divided by the frequency response of the three detection systems to remove the detection system responses, which are measured with the californium source between and adjacent to the two detectors away from significant reflection by walls and floor.. This will require analysis of the original data. 


\section{REFERENCES}

A.1. J. T. Mihalczo, J.A. Mullens, J. K. Mattingly, and T. E. Valentine, "Physical Description of Nuclear Materials Identification System (NMIS) Signatures," Nucl. Instrum. Methods Phys. Res., Sect. A, 450 (2-3), 531-555 (2000).

A.2 V. K. Paré and J. T. Mihalczo, "Reactivity from Power Spectral Density Measurements with Californium-252," Nucl. Sci. Eng., 56 (2), 213-218 (1975). 



\section{APPENDIX B. DETAILED SKETCH OF THE CALIFORNIUM IONIZATION CHAMBER}

Figure B depicts a Monte Carlo model of the californium ionization chamber from a previous International Criticality Safety Benchmark Program benchmark. The MCNP input file for this chamber is given in the benchmark SUB-HEU-SOL-THERM-001.

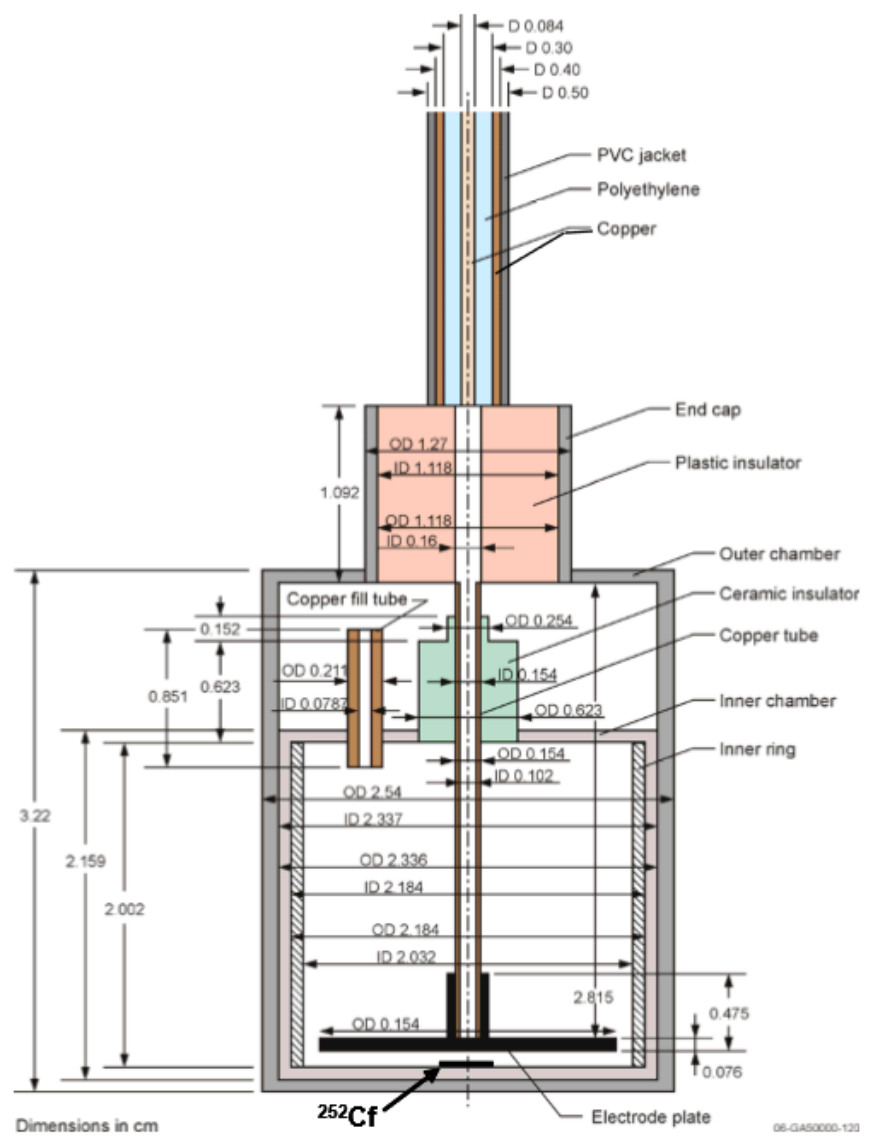

Figure B.1. Monte Carlo sketch of californium ionization chamber. 



\section{APPENDIX C. CALIFORNIUM SOURCE-DRIVEN-NOISE ANALYSIS}

\section{C.1 BACKGROUND}

This appendix presents a review of the californium source-driven noise analysis method, its original development, and present status. This method has its origins in time correlation function measurements, which is the time distribution of counts in one detector with respect to a previous count in the same or another detector. This was first suggested by Bruno Rossi during the Manhattan Project and is known as the two- and one-detector Rossi- $\alpha$ measurement [C.1]. Because it requires two counts, the measurement depends on the square of the detection efficiency. In $1968,{ }^{252} \mathrm{Cf}$ was deposited on one plate of a parallel plate ionization chamber, and its spontaneous fission provided a timing signal as to when neutrons were emitted. Therefore, using californium in this way provided the basis for a randomly pulsed neutron source [C.2], which was used to measure the time distribution of counts in a detector with respect to a count in the californium ionization chamber. This measurement acquired data much faster than the Rossi- $\alpha$ because it depended on the detection efficiency and not its square, and the efficiency for counting spontaneous fission of californium was near $100 \%$.

In 1975, the author joined the research group doing reactor noise [C.3] measurements in the frequency domain rather than the time domain. These measurements had some advantages in that when the fission rates were so high, the fission chains overlapped and could not be distinguished in the time domain. The auto- and cross-power spectral densities in the frequency domain are just the Fourier transform of the autocorrelation function and the cross-correlation functions in the time domain. These frequency domain measurements were developed for reactors operating at high power. This method was designated as the californium source-driven noise analysis and was used from about 1975 to 2000 to measure the subcriticality at eight US Department of Energy facilities [C.4].

In these measurements, the californium source ionization chamber and two detectors were used. This technique measured a ratio of spectral densities that was independent of detection efficiency, and thus avoided the problems of neutron source multiplication methods [C.5], which had been used for decades to monitor the approach to critical in critical facilities and in the initial startup of reactors. In about 1984, the first time domain measurements were performed with nuclear weapons/components of highly enriched uranium metal using a timed-tagged ionization chamber, and through the 1980s and to 2017, the Nuclear Materials Identification System (NMIS) was developed. The number of detectors initially increased to five. Since the fission chain decay was so rapid in these systems and these systems were subcritical, most of the analysis used the time domain measurements where smaller californium sources were used. However, the frequency analysis result capability was maintained in the NMIS software. Mihalczo, Mullens, Mattingly, and Valentine (2000) provide a physical description of the signatures acquired by NMIS [C.6].

The use of a time-tagged californium ionization chamber with its isotropic emission of neutrons created background problems for some measurements. In 2004, analysis by James Mullens [C.7] indicated that with a time and directionally tagged neutron generator, the NMIS system could be expanded to perform neutron imaging. The time and directional tagging were accomplished by detecting the alpha particle from the deuterium-tritium reaction that is emitted $\sim 180$ degrees from the neutron emission [C.8]. The NMIS software for acquiring (DAUI) and interpreting (IDAS) data was modified to multiplex signals depending on their width. The NMIS capability at that time was 10 input channels capable of 8 or more detectors per channel. This allowed using a row of 16 alpha pixels to define a fan beam of neutron cones, each with a separate direction and using a radial arc of 32 detectors that can be used for imaging. This imaging work was originally supported by the Y-12 National Security Complex for nuclear material and control applications and later by the US Department of Energy Office of Nuclear Verification.

Additionally, NMIS employed eight additional large detectors that could be used for active and passive 
time correlation measurements. The US Department of Energy Office of Nuclear Verification then supported a more friendly treaty usable system designated as the Fieldable Nuclear Material Identification System [C.9]. In 2006, a more advanced highly pixelated system was developed by Paul Hausladen and coworkers [C.10].

\section{C.2 CALIFORNIUM SOURCE-DRIVEN NOISE ANALYSIS METHOD}

This method was originally developed in 1975 for subcriticality determinations for three detectors-a time-tagged californium source and two detectors. The development of the equations for this method is given in the literature [C.11].

\section{C.3 NOISE EQUIVALENT SOURCE}

The point kinetics equations presented use the ORNL version of the noise-equivalent source. Another alternate version of the noise-equivalent source was developed by Akcasu and others [C.12]. This latter version supposedly has a better theoretical foundation. However, for highly subcritical systems, its use results in overestimation of the neutron multiplication. In 1990, researchers at Knolls Atomic Power Laboratory (KAPL) performed a completely independent analysis and compared the results of interpretation of measurements by both methods [C.13]. Basically, at neutron multiplication factors above 0.80 , both point kinetics methods give similar results but not below 0.80 . This will be illustrated in subsequent sections of this appendix.

\section{C.4 HIGHLY ENRICHED URANYL NITRATE SOLUTION TANK EXPERIMENT}

A photograph of the tank that contained uranyl nitrate solution is given in Figure C.1. The measurements were performed with external plastic scintillation detectors detecting leakage neutrons above $1 \mathrm{MeV}$ and gamma rays and was also performed with external ${ }^{3} \mathrm{He}$ proportional counters detecting the lower-energy spectrum of leakage neutrons. These results for measurements as a function of solution height, which are a ratio of spectral densities that can be interpreted to obtain the neutron multiplication factor, are shown in Table C.1 and in Figures C.2 and C.3. The results show the agreement with the calculated neutron multiplication factors. 


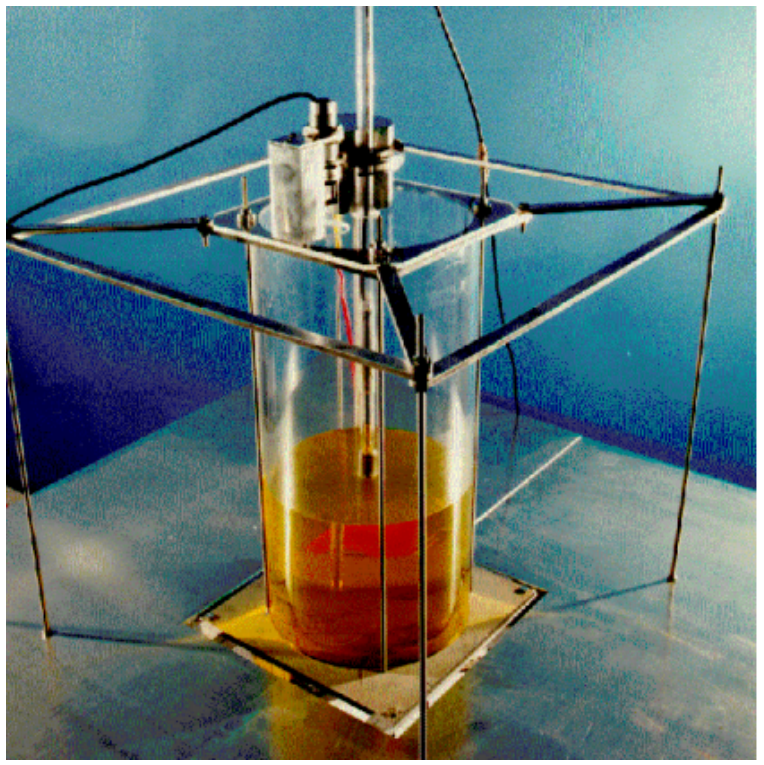

Figure C.1. Highly enriched uranyl nitrate solution tank without external detectors and the californium source at the top of the solution (solution color distorted from actual yellow by red tape on the table behind the tank).

Although the source is at the bottom of the solution, a location where point kinetics should not be valid, most of the coincidences come from fission chains with large number of fissions that are distributed spatially like the fundamental mode, even though the source is at the bottom of the solution.

Table C.1. Measured ratios of spectral densities at low frequencies and neutron multiplication factors from static measurement with the source at the bottom of the solution

\begin{tabular}{|c|c|c|c|c|c|}
\hline \multirow{2}{*}{$\begin{array}{l}\text { Solution } \\
\text { Height } \\
\text { (cm) }\end{array}$} & \multicolumn{2}{|c|}{ Ratio of Spectral Densities" } & \multicolumn{2}{|c|}{$\begin{array}{l}\text { Neutron Multiplication } \\
\text { Factors, } k_{\text {eff }}{ }^{b}\end{array}$} & \multirow{2}{*}{$\begin{array}{c}\text { Number of } \\
\text { Data Blocks } \\
\qquad\left(10^{3}\right)\end{array}$} \\
\hline & $\begin{array}{c}{ }^{3} \mathrm{He} \text { Detectors } \\
\left(10^{-4}\right)\end{array}$ & $\begin{array}{c}\text { Scintillators } \\
\left(10^{-4}\right)\end{array}$ & ${ }^{3} \mathrm{He}$ Detectors & Scintillators & \\
\hline $\begin{array}{l}29.2 \\
25.8 \\
20.3 \\
15.3 \\
10.1\end{array}$ & $\begin{array}{r}453 \pm 12(5) \\
767 \pm 40(5) \\
1590 \pm 20(5) \\
2896 \pm 90(5) \\
4508 \pm 90(5)\end{array}$ & $\begin{array}{c}436 \pm 5(2) \\
774 \pm 20(2) \\
1616 \pm 10(6) \\
2843 \pm 10(10) \\
4477 \pm 60(10)\end{array}$ & $\begin{array}{l}0.952 \pm 0.002 \\
0.924 \pm 0.005 \\
0.853 \pm 0.005 \\
0.732 \pm 0.015 \\
0.535 \pm 0.030\end{array}$ & $\begin{array}{l}0.954 \pm 0.001 \\
0.923 \pm 0.003 \\
0.850 \pm 0.005 \\
0.738 \pm 0.010 \\
0.540 \pm 0.027\end{array}$ & $\begin{array}{l}20 \\
20 \\
20 \\
40 \\
20\end{array}$ \\
\hline $\begin{array}{l}9.8 \\
9.0 \\
7.5 \\
6.5 \\
5.7\end{array}$ & $\begin{array}{l}--- \\
--- \\
--- \\
--- \\
---\end{array}$ & $\begin{array}{l}4723 \pm 60(10) \\
4960 \pm 60(10) \\
5293 \pm 210(10) \\
5650 \pm 60(10) \\
5943 \pm 360(10)\end{array}$ & $\begin{array}{l}--- \\
--- \\
--- \\
--- \\
---\end{array}$ & $\begin{array}{l}0.505 \pm 0.030 \\
0.472 \pm 0.035 \\
0.414 \pm 0.055 \\
0.346 \pm 0.049 \\
0.278 \pm 0.097\end{array}$ & $\begin{array}{r}7 \\
100 \\
40 \\
60 \\
55\end{array}$ \\
\hline
\end{tabular}

${ }^{a}$ Values in parentheses are the upper limit of the frequency range in kilohertz over which the ratio was averaged. The precision given is one standard deviation of the mean. Uncertainties in the neutron multiplication factor are from the statistical precision of the ratio of spectral densities and the uncertainties in the parameters required to infer the neutron multiplication factor. 


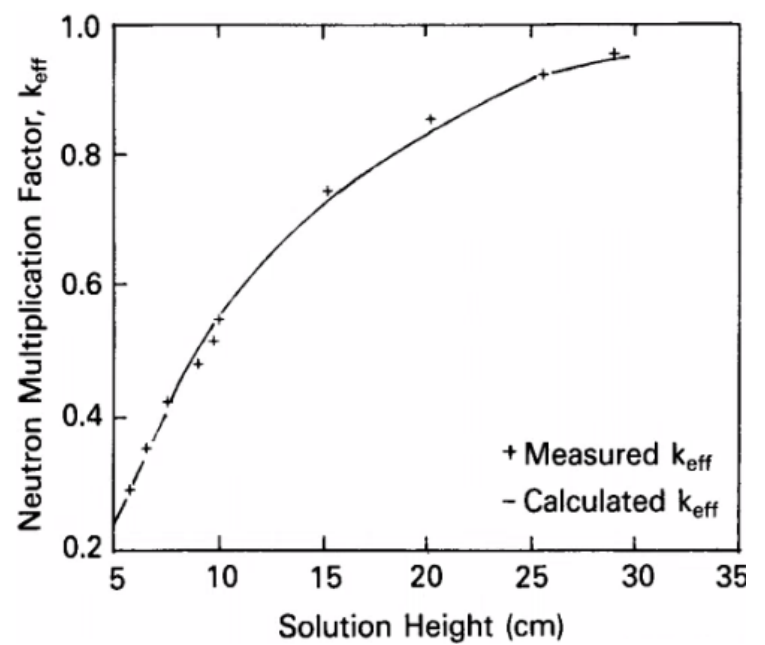

Figure C.2. Comparison of neutron multiplication factors obtained for the Pare/Mihalczo formulation of detection effects from static measurement with two ${ }^{3} \mathrm{He}$ proportional counters adjacent to the tank detecting leakage neutrons and with the source at the bottom of the tank. 


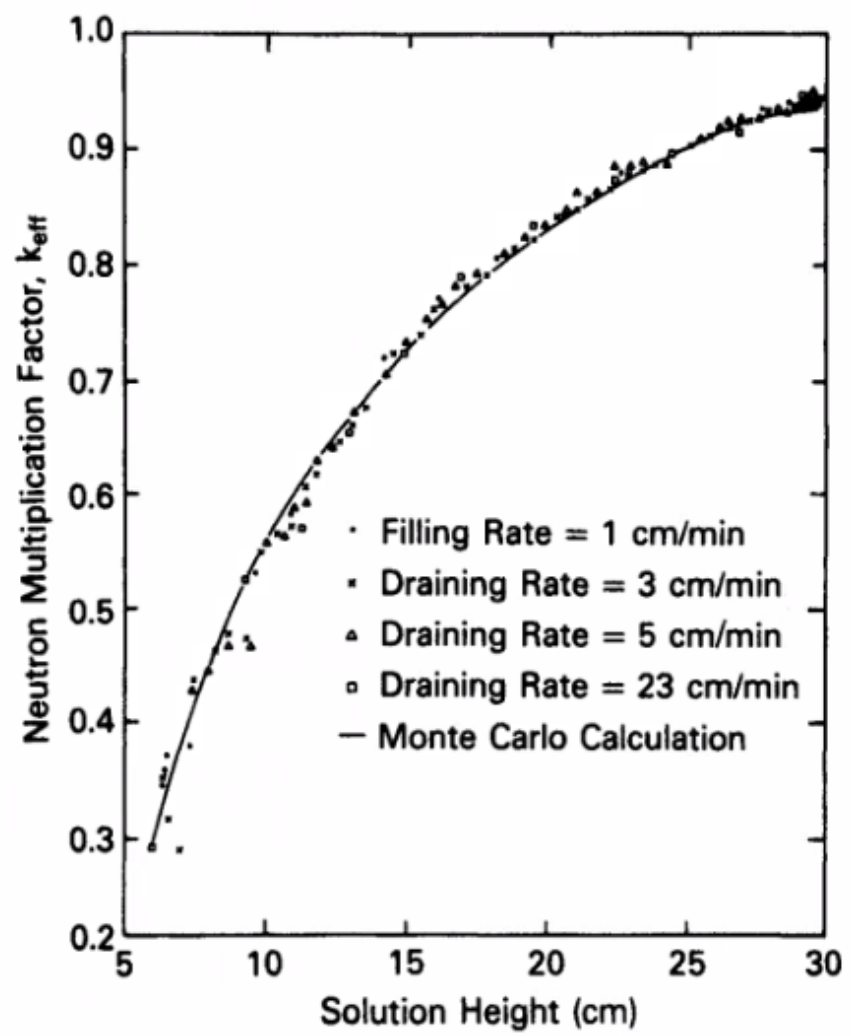

Figure C.3. Comparison of neutron multiplication factors obtained for the Pare/Mihalczo formulation of detection effects from dynamic measurement with two fast plastic scintillators adjacent to the tank detecting and gamma rays and the californium source at the bottom of the tank with calculations. (For these detectors, more than half of the coincidences are with a first detection in the coincidence being a gamma ray and the second

Notably, the measured ratio is the same as predicted by the theory for the ${ }^{3} \mathrm{He}$ proportional counters detecting lower-energy neutron spectrum neutrons and fast plastic scintillators detecting gamma rays and fast neutrons. Both these systems are detecting leaking prompt neutrons, and the scintillators are also detecting leaking prompt gamma rays. In fact, calculations have shown that most plastic scintillator coincidences involve only one neutron and gamma rays (private communication report from P. M. Keates, UK, to J. Mihalczo, Oak Ridge National Laboratory, 2019, available from John Mihalczo). Recent Monte Carlo simulations have shown that for these type of scintillation detectors, more than half of the coincidences the first detection in the coincidence is a gamma ray (personal communication Shaun Clarke, University of Michigan, January 2021)

The measured and the calculated neutron multiplication factors are in excellent agreement. The neutron multiplication factors from the dynamic measurement as the tank was drained with the fast plastic scintillators and the californium source on the bottom of the tank are compared with calculations in 
Figure C.3. For all draining rates, the measured neutron multiplication factors agree, and they also agree with the calculations.

\section{C.5 INTERPRETATIONS BY KNOLLS ATOMIC POWER LABORATORY (KAPK) USING BOTH POINT KINETICS FORMULATIONS AND COMPARISON WITH CALCULATIONS}

A report by Sutton and others from KAPL [C.13] also evaluated the ratio of spectral densities to obtain, using both the Pare/Mihalczo point kinetics formulations and the Akcasu/Stolle formulation. This report was independent of ORNL (i.e., all the necessary parameters to infer the neutron multiplication factor were obtained by Sutton and coauthors independent of ORNL for the ORNL interpretation). KAPL researchers also calculated the neutron multiplication factor by the KAPL Monte Carlo code (RACER) and compared it with the two different point kinetics formulations of interpretation of the ratio of spectral densities. Their calculated neutron multiplication factors agreed with their interpretation of the ratio of spectral densities using the ORNL formulation. The interpretation using the formulation of KAPL and others gave neutron multiplication factors that were much higher than those from the Pare/Mihalczo interpretation at the low-neutron multiplication factor values. These comparisons are presented in the Figure C.4. At a solution height of 4 in., the Paré/Mihalczo formulation gave a $\mathrm{k}_{\text {eff }}$ of 0.56 , compared with 0.69 for the KAPL interpretation using Sutton's formulation. RACER Monte Carlo-calculated neutron multiplication factors agree with the Mihalczo/Pare formulation of the noise-equivalent source formulation. At neutron multiplication factors above 0.85 , the inferred neutron multiplication from both point kinetics formulations are in better agreement. 


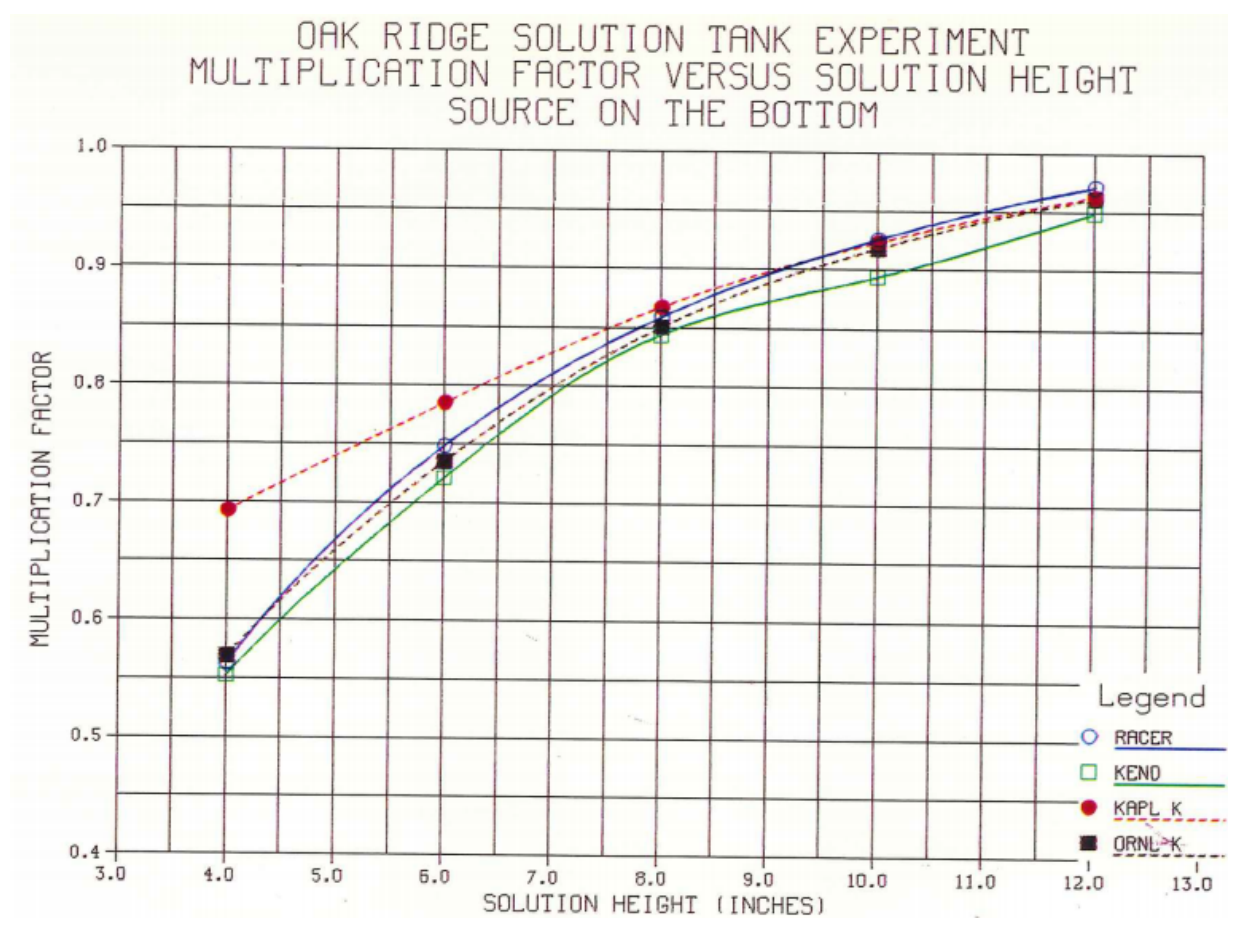

Figure C.4. Comparison of neutron multiplication factors from RACER Monte Carlo calculations with the two formulations. (Red circles are KAPL interpretation using the Akcasu/Stolle formulation, and black boxes are KAPL'S formulation using the Pare/Mihalczo formulation.)

At low-neutron multiplication factors, the interpretation using the KAPL formulation gives results that do not agree with the RACER calculations. For a solution height of 4 in., the Akcasu-Stolle formulation gives a neutron multiplication factor of 0.69 , and the RACER Monte Carlo calculation gives 0.56 . The disagreement increases as the neutron multiplication decreases and starts below the $\mathrm{k}_{\mathrm{eff}}$ of 0.85 .

\section{C.6 HIGHLY ENRICHED URANYL NITRATE SOLUTION TANK EXPERIMENT}

Californium source-driven noise analysis subcritical measurements were performed with a tank of uranyl nitrate solution [C.14]. The solution concentration of uranium $\left(93.16 \mathrm{wt} . \%{ }^{235} \mathrm{U}\right)$ in the uranyl nitrate solution was varied in 16 steps from $13.70 \mathrm{~g}$ of ${ }^{235} \mathrm{U}$ per liter to $0.325 \mathrm{~g}$ of ${ }^{235} \mathrm{U}$ per liter and then 0.0 (water). To minimize the handling hazard, the solution had no free acid content. The inside diameter of the $0.32 \mathrm{~cm}$ thick SS tank was $76.1 \mathrm{~cm}$, and the inside height was $91.4 \mathrm{~cm}$. The tank had a bottom thickness of $1.27 \mathrm{~cm}$ with a $1.27 \mathrm{~cm}$ thick plastic lid to minimize evaporation. The height of the solution was $76.2 \mathrm{~cm}$. The neutron multiplication factor, $\mathrm{k}_{\text {eff }}$, varied from 0.91 to 0.0 . Californium source-driven noise analysis measurements $(\sim 160)$ were performed at each solution concentration with a variety of detectors, detector locations, and source locations. In the solution, two ${ }^{3} \mathrm{He}$ proportional counters in aluminum tubes were used and external to the tank, as well as plastic scintillators.

The results of the interpretation of the ratio of spectral densities from these measurements with both interpretations of the measurements are given in Figure C.5. Again, the Akcasu/Stolle formulation give 


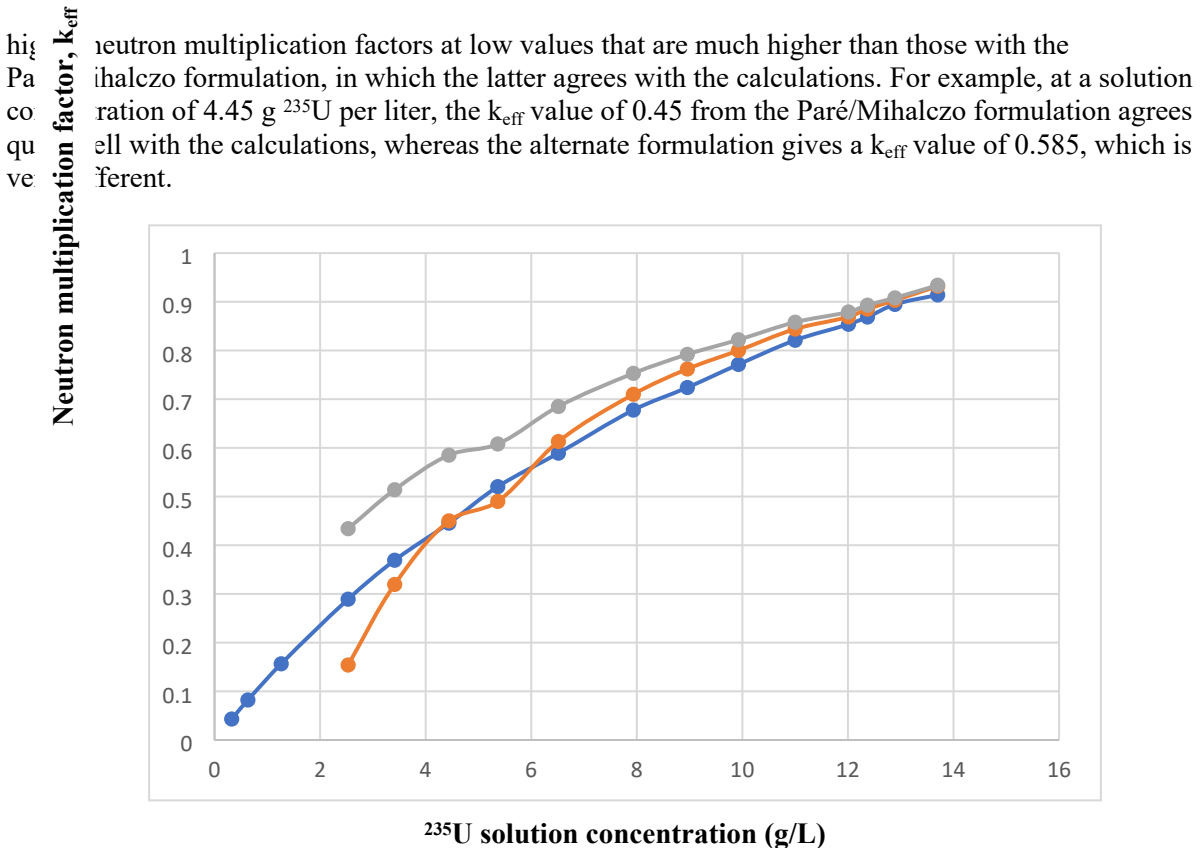

Figure C 5. Neutron multiplication factors from ratios of spectral densities with both formulations compared with calculations. (Red is interpretation with the Paré/Mihalczo formulation, gray is with the Akcasu-Stolle formulation, and blue is for calculations.)

A more general model has been used to determine the neutron multiplication factor from the measured results. The Monte Carlo method can be used to directly calculate the ratio of spectral densities and its uncertainty. This avoids the use of point kinetics and replaces it with a very general method that does not have the limitations of the point kinetics model. Some examples of this use of the more general model are given in Nuclear Energy Agency evaluate criticality safety benchmarks SUB-HEU-SOL-THERM-001 and SUB-HEU-Sol-THERM-002 [References C.15 and C.16].

\section{REFERENCES}

C.1. John D. Orndoff, "Prompt Neutron Periods of Metal Critical Assemblies," Nucl. Sci. Eng., 2, no. 4, $450-460$ (1957).

C.2. J. T. Mihalczo, "The Use of Californium-252 as a Randomly Pulsed Neutron Source for Prompt Neutron Decay Measurements,” Nucl. Sci. Eng., 53, no. 4, 393-414 (1974).

C.3. J. T. Mihalczo and V. K. Paré, "Theory of Correlation Measurement in Time and Frequency Domains with ${ }^{252} \mathrm{Cf}$," Ann. Nucl. Energy, 2, 97-105 (1975). [OSTI \#4243449]

C.4. V. K. Paré and J. T. Mihalczo, "Reactivity from Power Spectral Density Measurements with Californium-252," Nucl. Sci. Eng., 56, no. 2, 213-218 (1975).

C.5. J. T. Mihalczo, A Review of Methods for Treatment of Source Effects in the Modified Source Multiplication Method for Monitoring the Reactivity in Refueling the CRBR, ORNL-5568, Union 
Carbide Corp. Nuclear Division, Oak Ridge National Laboratory, September 1979. [OSTI \#5984287]

C.6. J. T. Mihalczo, J.A. Mullens, J. K. Mattingly, and T. E. Valentine, "Physical Description on Nuclear Materials Identification System (NMIS) Signatures," Nucl. Instrum. Methods Phys. Res., Sect. A, 450, nos. 2-3), 531-555 (2000).

C.7. J. A. Mullens, J. T. Mihalczo, and P. Bingham, "Neutron and Gamma Ray Imaging for Nuclear Materials Identification," Proc. of INMM 45th Annual Meeting (Northbrook, IL) (July 2004).

C.8. D. Koltick, S. Kane, J. Mihalczo, S. McConchie, E. Mace, and M. Lvovsky, "Production of an Associated Particle Neutron Generator with ZnO:Ga Alpha-Detector," IEEE SORMA West (Berkeley, CA) (June 2008).

C.9. D. Archer, C. Britton, Jr., N. Bull, M. Emery, M. Ericson, L. Fabris, E. Farquhar, S. Frank, D. Hurst, R. Lind, S. McConchie, J. Mihalczo, J. Mullens. E. Sword, and J. Radle, "The Imaging Detector Subsystem Electronics of the Fieldable Nuclear Materials Identification System (FNMIS)," IEEE 2012 Nuclear Science Symposium (Anaheim, California) (October 2012).

C.10.P. Hausladen, M. Blackston, J. Mullens, and J. Mihalczo "Multimodal Imaging with Tagged Fast Neutrons for Material Identification" Presentation 2012, CAARI 2012, August 5-10, 2012 (Ft. Worth, TX) (August 2012).

C.11.J. T. Mihalczo, E. D. Blakeman, G. E. Ragan, E. B. Johnson, and Y. Hachiya, "Dynamic Subcriticality Measurements Using the ${ }^{252} \mathrm{Cf}$-Source-Driven Noise Analysis Method," Nucl. Sci. Eng., 104, no. 4, 314-338 (1990).

C.12. A. Z. Akcasu and A. Stolle, "Langevin Equation Approach to Reactor Noise Analysis: Stochastic Transport Equation," Nucl. Sci. Eng. 113, no. 1, 31-55 (1993).

C.13. J. P Weinman and M. R. Mendelson, KAPL Monte Carlo Analysis of Subcritical Reactivity Measurements in the Oak Ridge Solution Tank, Knolls Atomic Power Laboratory, KAPL-M-7759 (September 1990).

C.14. J. T. Mihalczo, W. T. King, E. B. Johnson, and E. D. Blakeman, "Subcriticality Measurements for a Fuel Solution Tank with Changing Concentration using the Cf-252-Source-Driven Noise Analysis," Meeting of the American Nuclear Society, San Francisco, Trans. Amer. Nucl. Soc. 45, 237-238 (1983).

C.15.E. D. Blakeman and T. E. Valentine, Unreflected High Enriched Uranyl Nitrate Subcritical Noise Measurements, SUB_HEU_SOL_THERM-001, NEA/NSC/DOC/(95)03/II Volume II (2019).

C.16. E. D. Blakeman, Subcritical Noise Measurements for Two Coaxial Cylindrical Tanks Containing 93.1 wt. \% Uranyl Nitrate Solution, SUB_HEU_SOL_THERM-002, $\mathrm{NEA} / \mathrm{NSC} / \mathrm{DOC} /(95) 03 / \mathrm{NSC} / \mathrm{DOC}$. 



\section{APPENDIX D. COMPOSITION OF THE CONCRETE}

The concrete in the floors was modeled at Los Alamos National Laboratory as a standard composition Portland concrete; this information was gathered from a National Institute of Standards and Technology (NIST) materials database. The density was $2.3 \mathrm{~g} / \mathrm{cm}^{3}$. The elemental composition is given in Table D.1. The water content of standard Portland cement should probably be reduced because of the high desert environment of KIVA 1.

Table D.1. Elemental composition of the concrete

\begin{tabular}{|c|c|}
\hline Element & Weight Percent \\
\hline $\mathrm{H}$ & 1 \\
\hline $\mathrm{C}$ & 0.1 \\
\hline $\mathrm{O}$ & 52.9107 \\
\hline $\mathrm{Na}$ & 1.6 \\
\hline $\mathrm{Mg}$ & 0.2 \\
\hline $\mathrm{Al}$ & 3.3872 \\
\hline $\mathrm{Si}$ & 33.7021 \\
\hline $\mathrm{K}$ & 1.3 \\
\hline $\mathrm{Ca}$ & 4.4 \\
\hline $\mathrm{Fe}$ & 1.4 \\
\hline Total & $\mathbf{1 0 0}$ \\
\hline
\end{tabular}


Approved for public release.

Distribution is unlimited. 